\title{
JUAN ARAÑÉS SALLÉN (*ZARAGOZA?, 1580a; †LA SEU D’URGELL?, 1649p). HACIA UNA NUEVA BIOGRAFÍA CRÍTICA DE UN DESTACADO MÚSICO ESPAÑOL DEL SIGLO XVII
}

\author{
JUAN ARAÑÉS SALLÉN (*ZARAGOZA?, 1580a; †LA SEU D’URGELL?, 1649p). \\ TOWARDS A NEW CRITICAL BIOGRAPHY OF A RELEVANT SPANISH \\ MUSICIAN FROM THE SEVENTEENTH CENTURY
}

\author{
Francisco Javier Cerveró Martínez \\ Conservatorio Superior de Música “Joaquín Rodrigo" de Valencia \\ javicervero@hotmail.com \\ ORCID iD: https://orcid.org/0000-0003-0744-7318
}

\begin{abstract}
Resumen
El compositor Juan Arañés ha sido transmitido por la historiografía como un autor de especial relevancia y significación dentro del contexto panhispánico. De hecho, se le menciona en múltiples tratados teórico-musicales. Sin embargo, todavía no existía una biografía crítica y contrastada sobre él mismo en la actualidad. Bien es cierto que los meros datos biográfi cos que han llegado hasta nosotros han transmitido no pocos errores, y que, habida cuenta de la movilidad y oscuridad de su trayectoria profesional, aún plantea no pocas lagunas e interrogantes. En el transcurso de esta investigación se han podido desvelar algunos de los errores transmitidos, cubrir ciertas lagunas y encontrar una información realmente valiosa (particularmente en archivos de Zaragoza, La Seu d'Urgell y Tortosa). El presente estudio fi ja y establece por primera vez una biografía crítica del compositor.

\section{Palabras clave}

Arañés, música, barroco, España, maestro de capilla, tonos, villancicos, guitarra, Roma, Robletti.
\end{abstract}

\section{JUAN ARAÑÉS SALLÉN (*ZARAGOZA?, 1580A; †LA SEU D'URGELL?, 1649P)}

A pesar de que se trata de un autor que ha merecido cierta atención a lo largo del tiempo (siquiera sea a través de meras citas), las referencias biográficas sobre Juan Arañés son, todavía a día de hoy, escasas e inciertas.

\begin{abstract}
The information about the Spanish composer Juan Arañés has been transmitted by the historiography giving the idea of an author of particular relevance and significance in the Pan-Hispanic context. In fact, he is mentioned in many music treatises. However, there was not yet a critical and reliable biography available on him. It is true that the mere biographical data which have arrived until nowadays, have conveyed many mistakes, and, because of the mobility and darkness of his professional career, they remain quite a few gaps and questions. In the course of this research, I have been able to unlock some of the transmitted errors, cover certain gaps and find a really valuable information (particularly in archives of Zaragoza, La Seu d'Urgell and Tortosa). This article sets and establishes, for the first time, a critical biography of the composer.
\end{abstract}

Key words

Arañés, Music, Baroque, Spain, maestro de capilla, tonos, villancicos, guitar, Rome, Robletti.

Se trata de un compositor español activo en la primera mitad del siglo XVII, de quien se desconoce con certeza su origen y primera formación musical. Según Enric Querol, - que basaba su hipótesis en un documento conservado en el Archivo Histórico Comarcal de les Terres del Ebre, de Tortosa (Tarragona), 
datado en 1609-, Arañés sería "originario de Zaragoza"1. En dicho documento, se menciona a los padres de nuestro músico como vecinos de Zaragoza, de donde la suposición de la procedencia del joven Arañés.

Según estos datos, Juan Arañés Sallén, vecino de Tortosa en 1609, sería hijo de Juan Arañés, mercader, y de Mariana Sallén, ambos vecinos de Zaragoza. Además, en este documento se da noticia de la existencia de su hermana Magdalena, entonces casada, la cual también residía en Tortosa en aquella época:

[14 DE AGOSTO DE 1609] [Fol. 1r.:] "Dictis die et anno. / Sepan quantos esta carta de poder vieren que nosotros Joan / Arânes presbitero maestro de capilla en la Sta. Iglesia de Tortosa / Madalena Aranes muger de Hieronimo Verdejo vezino de la Ciudad / de Tortosa hermanos hijos legittimos y naturales de Juan Aranes merca / der y Marianna Sallen vesinos de la Ciudad de Caragoca. De ñro buen gra /do y cierta scientia [q otor]gamos y conocemos que damos y otorgamos todo $\widetilde{n r o}$ po- / der [?] libre [?] y bastante sepan que nosotros le tenemos y mejor y mas cupli- / damente que podemos y debemos dar y de dicho mas puede y deue valer a los señores / [?] Joan [?] canonigo de la Sta. Iglesia de Caragoca y Joan Oquen- / do [presente en las?] mismas [?] ausentes bien assi como si fuesen presêtes y al / dicho Hieronimo Verdejo con cuya voluntad y consentimiento y dicha Ma- / dalena Arañes su muger otorgo el pnte poder y a cualquier dellos de por si y insoli- / dum de tal manera que lo que el uno dellos comensare pueda qualquier de los / demas proseguir y lleuar a su deuido effecto y cuplimiento. A saber es para que / por nosotros y en nuestros nombres puedan pedir recebir demandar cobrar y hauer / de qualesquier personas de qualquier grado estado o condicion que sean en qua- / lesquier partes o lugares del Reyno de Aragon residentes todas y quales / quiere cantidades de dinero que de pnte nos deuen o enlo por venir deueran / assi por virtud de cartas de encomiendas como de otras qualesquier / scripturas publicas o particulares y especialmente y expressa aquellos / quatro mil sueldos jaqueses que se nos deuen y competen por razon de una / manda o legado que Bernardo Sallen nuestro aguelo en su ultimo testamento / a que nos referimos hizo a la dicha Marianna Sallen su hija y madre / nuestra en cuyo drecho y bienes nosotros surçedemos. E de todo aquello / que por nosotros y en nros nombres cobraren puedan dar y otorgar una / y muchas cartas de pago y baste y de finyquito con difinicion y can-/ celacion de qualesquier obligaciones $\mathrm{y}$ escrituras ante qualesquier / escriuanos y notarios en la forma deuida y acostumbrada. E si para / la seguridad de la cobrança de los dichos quatro mil sueldos en caso / que hasta el dia de hoy no tenga lugar ni el plazo sea cumplido con/ viniere que se agan en ñro fauor algunas obligaciones y

1 QUEROL (2006): 53. Enric Querol no menciona en el libro citado en qué documento concreto se ha basado para afirmar que Arañés era "originari de Saragossa", si bien, con posterioridad, él mismo me facilitó amablemente (lo que le agradezco especialmente) el protocolo notarial donde consta dicha información, el cual transcribo a continuación. escrituras / puedan los dichos señores procuradores nuestros o qualquier dellos / sin periuizio nuestro acceptarlas. E assi mesmo si para todo lo que / dicho es y cada casa o parte dello fuere necessario entrar en con- / tienda de juizio puedan los dictos ños procuradores y qualquier dellos / parecer ante qualesquier justicias, juezes y officiales, assi ecclesiasti- / cos como seglares en el dicho Reyno de Aragon jurisdiction exer- / cientes y en sus cortes y tribunales y pedir alcançar cumplimiento / de justicia y tratar cualesquier pleytos y causas por nosotros y en ñro / [Fol.1v.:] nombre hasta la sentencia diffinitiua y real execusion della con todas / las clausulas y facultades que para ello se requieran las quales queremos / hauer aqui por expressas y declaradas y para todo lo sobre / dicho [¿que solamente?] puedan sostituir un procurador o mas y aquellos / reuocar siempre que les fuere bien visto que quan cumplido y bastante / poder nosotros tenemos esse mismo le damos y otorgamos con todas sus / dependencias y emergencias, anexidades y conexidades y prometemos hauer / por rato valedero y firme agora y por todos tiempos todo lo que por los / dichos nuestros procuradores y qualquier dellos o los que ellos sostituye- / ren fuere por nosotros y en ñros nombres echo y otorgada y no lo reuocar/so obligacion de todos ñros bienes muebles y raizes auidos y por hauer / en testimonio de lo qual otorgamos la pnte carta ante el escriuano / publico y testigos de yusso dichos escritos la qual es fecha y otorgada / en la Ciudad de Tortosa a XIIIJ dias del mes de Agosto del ano / del nasimiento de त̂ro S.r jesuxpo mil seiscientos / y nueue siendo [prentes] por testigos [?] llamados / [?] Aranges [¿y Onofre?] Cabreros/ vezinos de la [?] ciudad de Tortosa".

Transcripción del documento notarial de 1609 (Archivo Histórico Comarcal de les Terres del Ebre) ${ }^{2}$

La primera referencia clara y documentada de la formación musical y pertenencia a una capilla musical del autor aparece citada por Pedro Calahorra ${ }^{3}$, que da cuenta de la entrada de Juan de Arañés (estudiante), como aprendiz de canto ${ }^{4}$ en la capilla de música de Jerónimo Muniesa ${ }^{5}$, de Zaragoza (lo cual parece reafirmar su origen zaragozano).

2 Puede verse una reproducción fotográfica del documento original en CERVERÓ (2017): I, 34-35.

3 CALAHORRA (1978): 2, 173-174.

4 Documento del notario Diego Fecet, año 1594, Archivo Histórico Provincial, Zaragoza, fol.607v. [Referencia ofrecida por P. Calahorra; en la actualidad, esta documentación se ubica en el Archivo de Protocolos Notariales de Zaragoza, en la Plaza del Justicia de dicha ciudad].

5 Jerónimo Muniesa (*Tardienta -Huesca-?, 1575a; †Zaragoza, 1595). Maestro de capilla de Zaragoza activo en la segunda mitad del siglo XVI. Fue maestro de canto de una de las muchas capillas que proliferaron en este siglo en Zaragoza y que según contaba el cronista Pascual de Mandura "se alquilaba por la ciudad para cada fiesta, por el interés y ganancia que de ello sacaba". Los niños y estudiantes firmaban con Muniesa como criados suyos para aprender el canto llano, así como el de órgano, con la obligación de ir a las iglesias adonde les llevara la capilla. Contó también con el bajón Juan Cristóbal, que le acompañaba en todas las ocasiones. Vivió en la zaragozana parroquia de la Magdalena, según una partida sacramental. Encontrándose enfermo, hizo un 


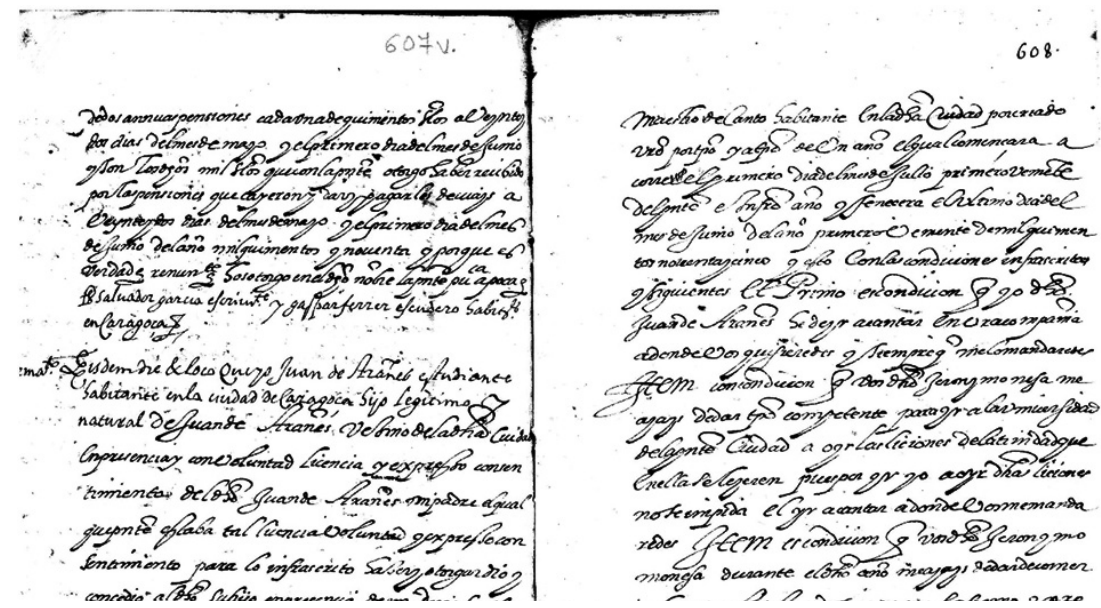

Figura 1. Comienzo del documento notarial en el que Juan de Arañés y Jerónimo Muniesa pactan las condiciones por las que el primero entra a formar parte de la capilla de música del Maestro Muniesa en 1594.

[Fol.607v.] Eisdem die \& loco. Que yo Juan de Arẫes estudiante / habitante en la ciudad de Caragoça, hijo legítimo y / natural de Juan de Aranes vezino de la dha ciudad / en presencia y con voluntad licencia y expresso consen / timiento del dho Juan de Arẫes mi padre el qual / que pnte estaba tal licencia voluntad y expresso con / sentimiento para lo infrascrito. Hazer y otorgar dio y / concedio al dho su hijo en presencia de mi diego fecet / not. $^{\circ}$ y testigos infr[ascrit]os. [?] si con [dicha] licencia de grados / certificado que me firmo con Vos Jeronymo monesa / [Fol.608r.] maestro de canto habitante en la dha ciudad por estado / vro por tô y a tô de un año el qual començara a / correr el primero dia del mes de Julio primero veniente / del pnte e infro año y fenecera el ultimo dia del / mes de Junio del año primero veniente de mil quinien / tos noventa y cinco y esto con las condiciones infrascritas / y siguientes. El Primo, es condición que yo dho / Juan de Arañes he de yr a cantar en vra compania / a donde vos quisieredes y siempre q me los mandaredes. / Item con condicion q vos dho Jerony monesa me / ayays de dar tôn competente para yr a la universidad / de la pnte ciudad a oyr las liciones de latinidad que / en ella se leyeren pues por yr yo a oyr dhas liciones / no se impida el yr a cantar a donde vos me manda / redes. Item es condición q vos dho Jeronymo / monesa durante el dho ano me ayays de dar de comer / y beuer assi estando sano como enfermo y pro / ueherme de medicos y medicinas assi estando sano / [Fol.608v.] como enfermo con esto que por cada uno de los dias que / huuiere estado enfermo durante el dho año / al fin

testamento prematuro en 1575 , en el que dice poseer obras de Morales y Guerrero. Tuvo un reconocido carácter polémico (existen noticias de algunos desplantes suyos hechos por exigencias económicas). Participó en los sangrientos sucesos de las Alteraciones de Zaragoza de 1591, seguramente activamente, por lo que fue exceptuado del perdón real. Según figura en su partida de defunción no recibió los sacramentos, ya que murió de forma violenta en 1595 en la ciudad de Zaragoza. Cfr.: CALAHORRA (1977): 79-80; CALAHORRA (1981): 9, 2389. de aquel hos aya de seruir dos de balde y sin / pagarme nada. Et assi teniendo y cumpliendo / vos dho Jeronymo monesa lo que conforme a lo sobre / dho soys tenido y obligado tener seruar y cumplir / prometo y me obligo de seruir y que hos seruire bien / y fielmente y q no me yre de vra casa y seruicio / durante el sobredho año y si me fuere y no lo cumpliere / quiero q fecha y no fechas pueda ser y sea procey / do y se procea a capcion de mi persona y aquella sea / presa detenida y compellida a cumplir el dho troo / en dha vra casa y seruicio y a pagarhos mil [libras] / jaq[uesa]s de pena en la qual incurra incontinenti / q sin cumplir el dho tiempo me huuiere ydo de / vra casa y seruicio. Et yo dho Jeronymo monesa / que alo sobredho pnte soy de grado y acepto a vos / dho Juan de aranes por criado mío por el sobredho / [Fol.609r.] tiempo y con las dhas condiciones las quales en quanto / a mi tocan prometo y me obligo tener seruar y cumplir / Et nosotros dhos Juan de aranês de una parte y / jeronymo monesa de la otra si expensas aquellas y / a lo qual tener y cumplir obligamos la una de nos / dhas partes a la otra et viceversa nras personas y todos / nrôs bienes assi muebles como ojetros y los quales quere / mos aqui haber y habemos por nombrados y conffron. ${ }^{\text {os }} \mathrm{y} /$ renunciamos y sometemonos y queremos sea va / riado Juizio y large./

[Dicho?] saluador garcia y Jũa Aranguren escriv. ${ }^{\text {tes }}$ ha $/$ bit. $^{\text {tes }}$ en Caragoça.//.

Precisamente, sobre el posible origen zaragozano de Arañés he podido localizar en las actas capitulares de la seo de Tortosa su nombramiento como nuevo maestro de capilla, donde se alude a la procedencia del músico, como presbítero de la diócesis de Zaragoza: 
[Fol.v. s/n:] presbyteri diocesis Caesaraugustanensis; / elegerunt et nominarunt [?] mera voluntate et beneplacito domini / Reverendi Capitulj in Magistrum / Capellae presentis ecclesiae: prefatum / Joannem Arañes, presentem et acceptan / tem: Assignantes ei distributiones / quotidianas tam diurnas quam noc- / turnas: processionesque ac Anniuer / saria: comensalis presentis Ecclesiae, ita quod / ei per mensatas pingantur et / soluantur dictas distributiones: pro / medietate Illius quantitatis quae / ex canonicatu Sancti officii Inqui / sitionis in uno quoque mense depingi consueuit in tabula / distributionum excepto lo estel; // et nihilominus providerunt quod admit / tatur ad celebrationem missarum de / tabula: prout caeteri comensales; / et ut missam quotidianam habeat dictus / Dominus Michael Sortor, Archidia / conus de Borriol, in capitulo presens, / dixit et se obtulit facere complemen / tum quolibet mense ex propriis pecunijs / dicto magistro capellae in missis quae / ei defecerint: celebrando ad eius / intentionem: concesseruntque dicti / dominj canonici Capitulares dicto / magistro capellae insignias commensalis / et locum in choro ad partem sinistram / superiorem inter caeteros commen / sales: Praeterea assignarunt / ei quatuor Panes parvos // canonicales per commensales quotidie / percipi solitos ex illis panibus / inter pauperes in Refectorio diui / di et erogari consuetis, quos Pani / cerius penes de quotidie retineat / et dicto magistro capellae tradat; / loco vero Portionis denariorum / assignarunt ei sexdecim libras / et decem solidos anno quolibet ex / pecuniis communis singulis mensibus sibi / solvendas: que omnia emolu / menta superius declarata / recipiat dictus magister capellae ad eius sustentationem, una / cum viginti libris annuis / de subventione per dictum dominum Don Hieronymum // Terça d.d. Archidiaconum de Culla ei oblatis et dare ac soluere / promissis in deliberatione / capitulari facta die Vigesimo octauo / mensis Junij proxime lapsa / in qua se stare et perseuerare / dixit, juxta formam et tenores / ipsius deliberationis. Et dictus venerabilis Joannes Arañes, ibidem presens, / prefatam electionem et nominationem / acceptando: obtulit se presenti / ecclesiae [?] viribus in / dicto magistri capellae munere / deseruire: et in habiles in cantu docere et instruere, prout eius / oneri incumbet, et per similes // magistros capellae officia sua ritte / exercentes est fieri consuetum".
[Margen:] Elección del maestro de capilla Juan Arañés. [Contenido:] Ítem, dichos señores canónigos capitulares, vista la suficiencia y los méritos del venerable Juan Arañés, sacerdote de la diócesis de Zaragoza, eligieron y nombraron de [...] mera voluntad y beneplácito de los señores reverendos del capítulo en maestro de capilla de la presente iglesia al mencionado Juan Arañés, presente y aceptando, y le asignaron las distribuciones cotidianas tanto nocturnas como diurnas, y procesiones y aniversarios, de comensal de la presente iglesia, de manera que le sean pagadas por mesadas dichas distribuciones, por mitades [dos veces al año], de aquella cantidad que del canonicato del Santo Oficio de la Inquisición también en un mes se acostumbra pagar en la mesa de distribuciones, exceptuado el estel [ila estrella?]; // y, no obstante, proveyeron que sea admitido a la celebración de les misas de la mesa conforme al resto de comensales; y como dicho Miquel Soror, arcediano de Borriol, presente al capítulo, tiene la misa cotidiana, dijo se ofreció a hacer un complemento cada mes de su pecunio a dicho maestro de capilla en las misas que a él le faltaran, celebrando a su intención; y concedieron dichos señores canónigos capitulares a dicho maestro de capilla insignias de comensal y sitio en el coro a la parte izquierda superior entre el resto de comensales. Además de eso, le asignaron cuatro panes canonicales pequeños // que se suelen recibir cuotidianamente por los comensales de aquellos panes que se suelen dividir y repartir entre los pobres al refectorio, los cuales retenga el panadero en su poder diariamente y entregue al dicho maestro de capilla; pero en lugar de porción pecuniaria, le asignaron dieciséis libras y diez sueldos en cada año de les pecunias comunes, pagadores mensualmente; que dicho maestro de capilla reciba todos los emolumentos más arriba declarados para su manutención, a veinte libras anuales de subvención que a él [Arañés] son ofrecidos y prometidos de dar y pagar por dicho señor Jerónimo Terça, d.d., arcediano de Culla, en deliberación capitular hecha en el día veintiocho de junio pasado, en la cual idea [el arcediano] dijo que se mantenía y perseveraba. Y dicho venerable Joan Arañés, presente en el mismo lugar, aceptando la antes dicha elección y nominación, se ofreció a la presente iglesia [...] señores servir dicho oficio de maestro de capilla, y enseñar e instruir en el canto a los inhábiles, según a su trabajo corresponde, Y por semejantes maestros de capilla acostumbran hacer.

Transcripción del nombramiento de Juan Arañés (1604) como maestro de capilla de la catedral de Tortosa (Tarragona), $(E-T O \text {, actas capitulares, } 25.08 .1604, \text { s.f. })^{6}$

Nuevamente según Enric Querol ${ }^{7}$, en dos documentos sueltos del Archivo Diocesano de Tortosa, ofrece datos del nombramiento de Juan Arañés como "mestre de capella" de aquella seo catalana el 25.08.1604; lo que confirma con otros documentos el anteriormente presentado, procedente de las actas capitulares, el cual es, hasta la fecha, la primera fuente documental de que

6 Pueden verse las fotos de las actas capitulares originales en CERVERÓ (2017): I, 37-39.

7 Que remite al Archivo Diocesano de Tortosa (carpeta "Mestre de Capella”), aunque sin dar la signatura. se dispone en la que aparece nombrado como maestro de capilla. Otra fuente en este mismo sentido es el documento notarial (véase el procedente del Archivo Histórico Comarcal de les Terres del Ebre, también citado e ilustrado anteriormente), de agosto de 1609, donde ya se definía a Juan Arañés como presbítero, es decir, sacerdote, y maestro de capilla en la Santa Iglesia de Tortosa. 


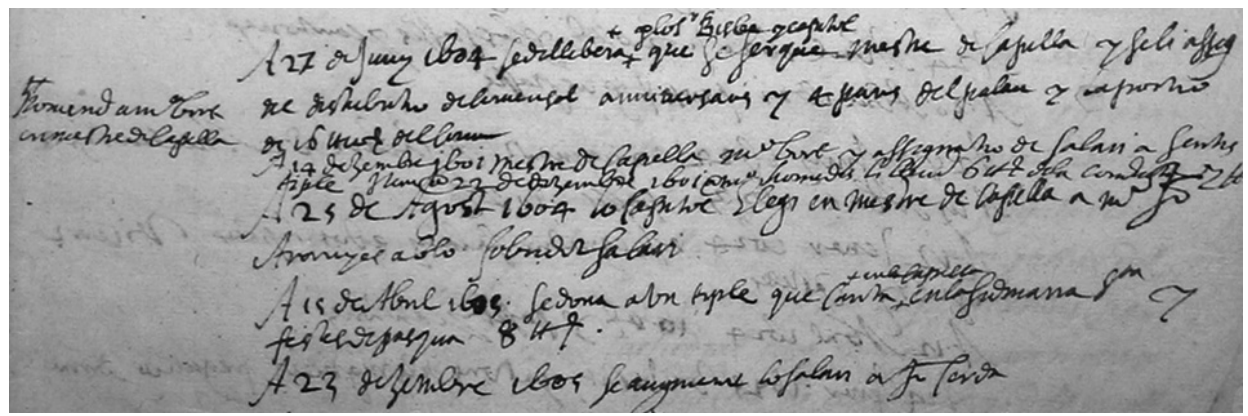

Figura 2. Documento suelto (Archivo Diocesano de Tortosa), con el nombramiento de Juan Arañés como maestro de capilla de la catedral de Tortosa (25.08.1604)

"[Acta capitular, s/f:] [Margen:] "Nomendament / en mestre de Capella"] [Contenido:] "A 27 de Juny 1604 se dellibera + que lo Sr. Bisbe y Capitol + que se serque Mestre de Capella y se li assig / ne distributio de comensal anniuersaris y 4 pans del palau y la portio / de $16 £ 10$ s del [Comun] / A 14 dezembre 1601 Mestre de Capella $\mathrm{M}^{\mathrm{o}}$ bort y assignatio de salari a gentis / tiple Item a 22 de dezembre $1601 \mathrm{a} \mathrm{M}^{\circ}$ homedes li lleua $6 £$ s de la Com[?][?] £s / A 25 de Agost 1604 lo Capitol Elegi en Mestre de Capella a $\mathbf{M}^{\mathrm{o}} \mathrm{Jo}$ [an] / Aranyes ab lo sobredit salari / A 15 de abril 1605 se dona a un tiple que canta + en la Capella + en la Semana $S^{\text {ta }}$ y / festes de pasqua $8 £$ s / A 23 Dezembre 1605 se augmenta lo salari a Ju[an] Cerda".

Posiblemente, a juzgar por la fecha en que aparece ocupando su primer magisterio de capilla documentado (y considerando que para entonces tuviera, como poco, dieciocho años), hubiera nacido hacia 1586, o en fecha anterior a ésta (acaso, en torno a $1580 \ldots$...).

Después de esta primera etapa como maestro de capilla en Tortosa, parece demostrado que habría ejercido también el magisterio de capilla de la catedral de Lleida, entre 1614 y 1620 :

"La capella de Tortosa, en procés d'estudi per Marian Rosa quant al Barroc, sembla haver estat, sense que en puguem donar compte de les raons, especialment lligada a Saragossa i a Lleida. Entre els mestres de capella més destacats hi trobem Joan Aranyés. Originari de Saragossa, estigué a Tortosa en diverses etapes: del 1604 al 1614, any en què se n'anà a Lleida, i del 1634 al 1646, quan es va establir a la Seu d'Urgell"'. [Aunque conviene señalar que, a pesar de lo que aquí se dice, en 1646 todavía seguía en Tortosa, como podremos ver más adelante...].
Que Arañés estuvo en Lleida como maestro de canto, parece refrendado también por algunas citas de ámbito propiamente musical $^{9}$. Más concretamente, Juan Mujal incluye el nombramiento de "Joan Aranyès" como maestro de canto de la catedral ilerdense el 02.10.1614, sustituyendo a "Matheu Calbet" [Mateo Calvete]:

"Convocati domini Francesch Terre, locunteniente decani, p. Precentor Pastor, Castellbell, Mija, Pastor, Scola et Petrus Scola canonici capitulantes: Attento que per relationem cantorum examinatorum electorum Rdi. Capitulantes constat vener. Joannem Aranyes, presb. esse habilem et idoneum magistrum cantus, elegerunt et nominarunt in Magistro Cantus et Capella Ecclesiae Ilerdensis vener. Joannem Aranyes presb. cum onoribus et oneribus ad nutum Rdi. Capituli" 10 .

Entretanto, también he podido constatar, de primera mano y gracias a dos actas capitulares de la seo de Tortosa, que Arañés habría dejado la capital de las "Terres de l'Ebre" para marchar a Lleida: se cancela una obligación a su nombre, y se habla ya de su sustituto en Tortosa. En el caso de la elección de quien iba a cubrir su vacante, he podido localizar la siguiente documentación:
9 MUJAL (1975): 89. BERNARDÓ (1999): vol. 6, 946 10 Sobre Mateo Calvete, vid.: EZQUERRO (2006): 81-120. 

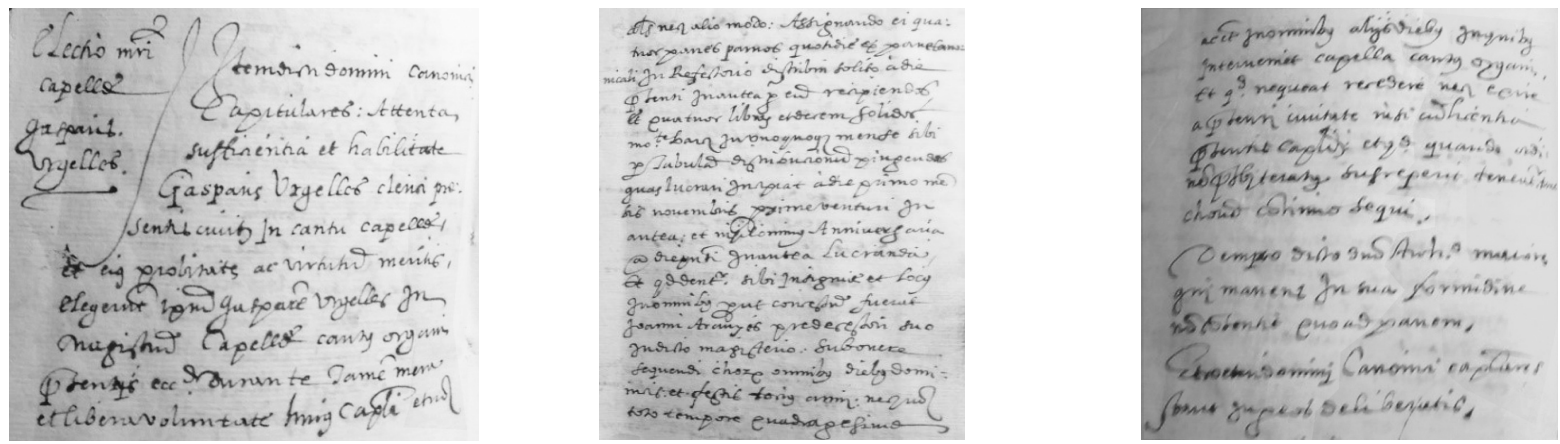

Figura 3. $\boldsymbol{E}-T O$, acta capitular de la seo de Tortosa, de 21.10.1614, con la elección de nuevo maestro de capilla en Gaspar Urgellés ${ }^{11}$, para sustituir a Juan Arañés

[Margen:] Electio magistri capellae Gasparis Urgelles.

[Contenido:] Item dicti domini canonici capitulares, attenta sufficientia et habilitate Gasparis Urgelles, clerici praesentis civitatis, in cantu capellae, et eius probitate ac virtutum meritis, elegerunt ipsum Gasparem Urgelles in magistrum capellae cantus organi presentis ecclesiae durante tamen mera et libera voluntate huius capituli etiam // alias nech alio modo, assignando ei quatuor panes parvos quotidie ex pane canonicali in refectorio distribui solito a die presenti inantea per eum recipiendos et quatuor libras et decem solidos monete Barchinone in uno quoque mense sibi per tabulam distributionum pingendos quas lucrati incipiat a die primo mensis novembris proxime venturi inantea; et nihilominus anniversaria a die presenti in antea lucranda, et quod dentur sibi insigniae et locus in omnibus prout concessum fuerat Joanni Aranyes, predecessori suo in dicto magisterio, sub onere sequendi chorum omnibus diebus dominicis et festis tocius anni nechnon toto tempore Quadragesimae // ac etiam in omnibus aliis diebus in quibus interveniet capella cantus organi et quod nequeat recedere nech exire a presenti civitate nisi cum licentia presentis capituli, et quod quando ordinem presbiteratus susceperit tenentur [...] chorum continuo sequi. Dempto dicto domino Archidiacono majore, qui manent in sua formidine, non contentit, quo ad panem.

Et coeteri domini canonici capitulares [...] super eos deliberatis.
[Margen:] Elección de maestro de capilla de Gaspar Urgellès. [Contenido:] Ítem, los dichos señores canónigos capitulares, considerando la suficiencia y habilidad de Gaspar Urgellès, clérigo de la presente ciudad, en el canto de capilla, y su honradez y méritos de virtudes, eligieron al mismo Gaspar Urgellès maestro de la capilla de canto de órgano de la presente iglesia durante, pero, la mera y libre voluntad de este capítulo, además ni en otro momento ni de otro modo, y le asignaron cuatro panes pequeños diarios del pan canonical que se suele distribuir al refectorio, recibidos per él [Urgellès] desde el día presente en adelante; y cuatro libras y diez sueldos de moneda de Barcelona en cada mes pagadores por la mesa de las distribuciones a ganar desde el primero de noviembre próximo en adelante; y también que gane los aniversarios desde hoy en adelante; y que le sean dadas insignias y sitio en todas las cosas según le concedieron a Juan Aranyés, predecesor suyo en dicho magisterio, con la obligación de asistir al coro todos los días, domingos y fiestas de todo el año ; también en todo el tiempo de Cuaresma y, además, en todos los otros días en que intervino la capilla de canto de órgano; y que esté imposibilitado para retirarse ni salir de la presente ciudad si no es con licencia del presente capítulo; y que cuando reciba la orden del presbiterado, esté obligado [...] a seguir puntualmente el coro.

A excepción de dicho señor ardiaciano mayor, quien permanece en su temor, no se contentó en relación al pan. Y el resto de señores canónigos capitulares [...] sobre ellos en las deliberaciones.

\section{Elección de Gaspar Urgellés como nuevo maestro de capilla de la catedral de Tortosa (21.10.1614),} para cubrir la vacante dejada por Juan Arañés

11 Gaspar Urgellés (fl.1614-1632p) ejerció como maestro de capilla de la catedral de Tortosa desde 1614 hasta 1629. Siendo maestro en Tortosa, ejerció en 1620 como examinador para elegir un maestro de capilla en la catedral de Lleida, puesto que recayó en Francesc Pradilles, natural de Tamarite de Litera. Por dicha labor, el cabildo ilerdense abonó 20 libras barcelonesas a Urgellés, para lo que dispuso "que sea expedido mandato a la administración de la almoina". En la seo de Tortosa, Urgellés organizó diversas representaciones de "negrillos" por las que percibió un pago "en ajuda del gasto que ha fet en vestir los negrillos que han ballat i cantat en estes festes de Nadal" el 12.01.1621, así como otras semejantes en 1623 y durante la Navidad de 1625. También, en 1629, el cabildo le otorgó 2 libras barcelonesas y 10 sueldos (E-TO, Fondo Notarial, Joan Jacint Martí, I, s.f.) por un Diálogo de les matines de Nadal de su composición. Y F. Pedrell cita que "en un libro de Pasiones de la Catedral de Tortosa se menciona este maestro como autor de la obra: Textus Passionis Dni. Nri.Jesu Xpi.quaterni vocibus concinendus Illi admodum $\mathrm{Rd}^{\circ}$. Capitulo almae sedis Dert[us]ae, a Gaspare Urgellés pbro. Dertus. ejusdemque sedis cantus moderatore dicatur" [PEDRELL: "Documentos inéditos para su Diccionario"]. Fue luego Urgellés "maestro de canto" (maestro de capilla) de la catedral de Lleida, admitido desde 24.11.1629 hasta al menos 1632, cuando se debatió capitularmente si se le forzaba a dimitir, aunque no hubo acuerdo en tal sentido, tras de lo cual parece que prosiguió en el puesto. El siguiente maestro de capilla documentado en Lleida, Jaime Ferrer, aparece ya en 1654, sin que se sepa si ingresaba sustituyendo a Urgellés, o si este último habría dejado el cargo anteriormente. MUJAL (1975): 90 y 93. CORTÈS (2002): vol. 10, 580. QUEROL (2006): 325 y 345. 
Y en el caso de la cancelación en Tortosa de una obligación a su nombre, consta que fue precisamente su cuñado, Jeroni Verdejo - a la sazón, notario de la ciudad de Tortosa - , quien se habría encargado de cancelar — en nombre de nuestro biografiado, y como avalista - la deuda de 15 libras que había dejado a deber al cabildo tortosino, antes de que el propio Arañés, como se refiere en el documento, ejerciera en ese momento el magisterio de capilla de la catedral de Lleida:

[Margen:] Obligación de Verdejo.

[Margen:] Fue cancelada la presente obligación con instrumento [escritura notarial] recibido por mí Pere Puigvert, notario y escribano en el día 17 del mes de febrero de 1615.

[Contenido:] En dichos día y año.

El honorable i discreto Jeroni Verdejo, notario, ciudadano de Tortosa constituido [...] libremente tenido y principalmente obligado por causa del reverendo Juan Aranyés, sacerdote, anteriormente maestro de capilla de la presente iglesia, aunque ahora de la seo de Lleida, cuñado suyo aquí presente, en 15 libras de moneda de Barcelona que ciertamente le restan pagar al reverendo capítulo de la seo de Tortosa de aquellas 25 libras de dicha moneda que dicho Juan Aranyés confesó deber al antedicho capítulo a causa de un préstamo de gracia que le había concedido [a Arañés] el cabildo, según consta en instrumento recibido por el notario y escribano abajo referido en el día 12 del mes de julio del año 1612 -porqué las restantes 10 libras, de deliberación capitular hecha en el día 10 de enero del año presente fueron perdonadas a dicho Arañés o mandas recibidas a cuenta por las causas y razones en aquella [escritura] contenidas -y queriendo que dicho Jeroni Verdejo [...] de la deuda ajena [...] hacer propia [...] le place y de voluntad suya [...] procedió gratis [...] y de buena fe prometió a dicho reverendo capítulo, ausente, y al notario infraescrito -estipulantes a la izquierda de prejucio, novación o derogación de dicho documento de deuda- que con Juan Aranyés, principal deudor, y sin él, además se tendrá [por obligado] solidariamente al antes dicho reverendo capítulo al pago de dichas 15 libras; así [...] que si de aquí al día o fiesta de la Natividad del Señor siguiente dicho Aranyés no pagara dichas 15 libras, en ese caso el mismo Verdejo las pague immediatamente en la presente ciudad de Tortosa pasado el plazo antes dicho al anterior dicho capítulo, sin dilación.

Estando presente dicho Joan Aranyés, quien en aquello antes expresado se conformó y lo aprobó, y confesó que era verdad. Fue obligado a dicho Verdejo en forma con [...] de los bienes [...] juramento y otros [...].

Testigos Pere Pau Giner, notario, y Josep Baduell, labrador, de Tortosa.

Transcripción de la cancelación de una obligación del presbítero Juan Arañés en Tortosa (14.10.1614) — siendo ya maestro de capilla de la catedral de Lleida - , con su

\section{correspondiente anotación o registro (17.02.1615). $E-T O$, actas capitulares ${ }^{12}$}

Al cabo del tiempo, el 11.05.1620, tenemos noticia - a través de J. Mujal - de su cese en Lleida, haciéndose cargo provisionalmente Juan Sala de aquel magisterio de capilla, mientras se procedía a la expedición de edictos de oposiciones para ocupar su vacante:

"Item deliberarunt que al Mestre de Capella se li alsen los salaris y que no se li done ninguna cosa, y tambe se li alse lo pa de Calonge y mesades y ques fassen edictes de la vagant de dit offici de Mestre de Capella pera notificarho a totes parts"13.

Entretanto, algunos autores como F. J. Fétis, R. Mitjana, R. Stevenson, o M. Honegger ${ }^{14}$, dan por cierto que Arañés estudió en la Universidad de Alcalá de Henares, donde habría realizado estudios de música y se habría ordenado como sacerdote, sin que indiquen en qué fechas pudo haberlo hecho (si bien conviene anotar que, al tratarse el de Castilla de un reino distinto a los pertenecientes a la antigua Corona de Aragón, con los que se le relaciona habitualmente, eso hubiera requerido - de cara a matricularse en la universidad y ordenarse sacerdote- que nuestro protagonista tuviera que someterse administrativamente, muy probablemente, a las correspondientes pruebas de limpieza de sangre y/o carta de naturaleza).

Surgen aquí varias posibilidades:

1) Que Arañés hubiera estudiado música, hubiera estado en la Universidad de Alcalá de Henares, y allí se hubiera ordenado como sacerdote, antes de 1604, en cuyo caso, tendría que haber nacido varios años antes de 1586 (pues, con solamente dieciocho años de edad, realizar tales estudios y ordenarse, no era una práctica frecuente, y hay que considerar que todavía estaba activo en 1649, lo que arrojaría, en dicho año, y supuesto su nacimiento en 1586, una edad de 63 años, a los que todavía se podrían añadir algunos más que le hubieran podido capacitar para ordenarse, como va dicho - algo no muy habitual teniendo en cuenta la reducida esperanza de vida de aquella época, aunque, ciertamente, no desdeñable-).

2) La opción de que Arañés hubiera realizado sus estudios musicales, presencia universitaria y formación eclesiástica ulterior en Alcalá, quedaría prácticamente descartada ${ }^{15}$. Al me-

12 Puede verse la reproducción del acta capitular original de la cancelación de dicha obligación en CERVERÓ (2017): I, 44.

13 MUJAL (1975): 90 y 93.

14 Vid., FETIS (1875): vol.1, 125. MITJANA (1920) [1993]: 116. STEVENSON (1980): vol. 1, 542. STEVENSON (2001): vol. 1, 837. HONEGGER (1988): vol.1, 32.

15 Podría incidir, acaso, en la posterior entrada de nuestro músico biografiado al servicio del duque de Pastrana, su hipotética estancia en la ciudad de Alcalá de Henares (?), la cual, por aquellas fechas, no hay que olvidarlo, constituía un importante centro político y cultural, 
nos, en el sentido de que se hubiera ordenado allí, como parece evidente que apuntan erróneamente Fétis, R. Mitjana, R. Stevenson y M. Honegger (salvo que lo hubiera hecho antes de 1604). Puesto que, cuando se le cita ya el 25.08.1604 como sacerdote, curiosamente, se dice que procede de la diócesis de Zaragoza, y nada se dice de Alcalá, ciudad que por otra parte, como ya queda apuntado, pertenecía a otro reino, con la consiguiente dificultad para eso, salvo que se hubiera argumentado todo muy bien documentalmente.

3) Con posterioridad a 1604 , había todavía un período en el que no se conocía el paradero de Arañés con garantías: entre 1620 y 1623, lo que suponía una notable laguna documental. Pero un artículo sobre el que se había reparado muy poco, publicado en 1994, aporta una información fundamental para la reconstrucción de la trayectoria de nuestro biografiado, en el sentido de que habría estado activo en Roma entre 1620 y 1624, en la iglesia de Santa María de Montserrat "de los aragoneses"16. Concretamente, se dice ahí que la iglesia de Montserrat ${ }^{17}$ dispuso entre sus compositores, a algunos españoles como Bartolomé Gistau, Joan Maria Noffra, Joan Araniés y Ramón Tríes, a quienes menciona también como organistas, ofreciendo unos escuetos datos relativos a sus fechas de actividad, y así, para el período de nuestro interés: Bartolomé Gistau (1621), Joan Araniés (1622), Ramón Tríes (1622) y Joan Maria Noffra (1623-1626).

En cuanto a la primera presencia romana de Arañés, hay que vinvularla pues, sin duda, a la iglesia de Montserrat. Ésta, institucionalmente, servía de centro de acogida para los peregrinos en Roma, sobre todo los pobres o enfermos (pues estaba provista también de un hospital), y para representantes de diversa procedencia y rango social, especialmente de los diferentes reinos de la Corona de Aragón (Aragón, Cataluña, Valencia y Mallorca). En aquel contexto, algunos españoles residentes en Roma - y muy particularmente, sus embajadores - , desde

sede de la célebre Universidad Complutense de Alcalá (con su imponente edificio renacentista), lugar en el que se asentaba el Tribunal del Santo Oficio de la Inquisición, emplazamiento de una intensa actividad editorial, sede de la relevante Iglesia Magistral -en la que, años más tarde, ejerciera su actividad el organista y teórico musical Andrés Lorente (*1624; †1703), también inquisidor y decano de la Facultad de Artes de aquella universidad, y luego, su discípulo, fray Antonio Martín y Coll $(* 1660 \mathrm{c} ; \dagger 1734 \mathrm{p})-$, y lugar, en suma, en el que residieran personajes como Miguel de Cervantes o Francisco de Quevedo, entre otros, en un marco estratégicamente situado cerca de la villa y corte de Madrid, por el que circulaban destacados personajes de la nobleza castellana. De hecho, como es conocido, la localidad de Pastrana, se sitúa en la actual provincia de Guadalajara (en la antigua Corona de Castilla), y precisamente, a medio camino en el trayecto entre ésta y la capital, Madrid, se situaba, curiosamente, Alcalá de Henares.

16 MOLÍ (1994): vol. 7, 9-125; citas concretas en pp. 16 y 92.

17 Santa Maria in Monserrato degli Spagnoli, es actualmente la iglesia nacional de España en Roma, pero, siglos atrás lo era en exclusiva de la antigua Corona de Aragón, mientras que la iglesia de Santiago lo era de la antigua Corona de Castilla. (Y al fusionarse ambas en el siglo XIX, quedaría la iglesia de Montserrat como templo para todos los españoles). comienzos del siglo XVII ${ }^{18}$, y con ánimo de gozar de la mejor música en su iglesia "nacional" 19 , iban a apoyar personalmente el nombramiento de compositores y organistas españoles en aquella iglesia, incluso encargando para ello la composición de determinadas obras musicales a los compositores entonces de moda en Italia, para conmemorar los acontecimientos más relevantes.

Por su parte, el III duque de Pastrana (a quien iba a dedicar en 1624 su obra impresa Arañés, su capellán "y maestro de capilla" ${ }^{20}$, había emprendido viaje a Roma con su séquito

18 Entre ellos, el V duque de Sessa, III de Baena, III duque de Soma, VII conde de Cabra, barón de Bellpuig, etc. Antonio Fernández de Córdoba Folch de Cardona y Anglesola Aragón y Requesens (*1550; $\dagger 1606)$-embajador de Felipe III ante la Santa Sede en 1590-1603-; el V marqués de Villena y V duque de Escalona, Juan Gaspar Fernández Pacheco $(* 1563 ; \uparrow 1615)$ - embajador de Felipe III ante la Santa Sede en 1603-1606-; el II marqués de Aitona, Gastón de Moncada y Gralla (*1554; †1626) - embajador de Felipe III en la corte de Paulo V en 1606-1609-; y muy en especial, el duque de Taurisano y conde de Castro, Francisco Domingo Ruiz de Castro $(* 1579 ; \dagger 1637)$, embajador en Roma en 1609-1616, que en 1615-1618 siguió una "política de aumento y conservación de la música" (es decir, de mecenazgo y protección a los músicos españoles que ampliaban estudios en Italia), mediante la promoción de magníficos encargos de composiciones musicales - que costeaban de su propio bolsillo-, el aumento extraordinario de salarios a los músicos, o la contratación de los mejores intérpretes, que llegarían a estar entre los mejores de Roma. Los siguientes embajadores de Felipe III ante la Santa Sede fueron -1616-1619- Gaspar Borja y Velasco (*1580; †1645), de la Casa de Borja - hijo del VI duque de Gandía-, que llegó a cardenal (1611) y primado de España, arzobispo de Sevilla (1632-1645) y de Toledo (1645), además de ejercer como virrey en Nápoles (1620); y el VII duque de Alburquerque, IV marqués de Cuéllar, VII conde de Huelma y de Ledesma, etc., Francisco Fernández de la Cueva $(* 1575 ; \dagger 1637)$-embajador en Roma, 1619-1623-, que llegó a ser virrey de Cataluña (1615-1619) y de Sicilia (1627-1632), y presidente de los Consejos Supremos de Italia y de Aragón.

19 En Santa María de Montserrat se favorecieron especialmente las celebraciones musicales para la Candelaria y para la Semana Santa.

20 Ruy III Gómez de Silva de Mendoza y de la Cerda (*Valencia, 1585; †Madrid, 1626), III duque de Pastrana (desde 1596), III de Estremera, IV de Francavilla y IV príncipe de Mélito, además de embajador en Roma. Hijo de Rodrigo de Silva y Mendoza (II duque de Pastrana) y Ana de Portugal y Borja. Su infancia la pasó entre Milán y Flandes con su padre, que era militar de profesión. A los once años era ya duque de Pastrana y fue llevado a España para que quedara al cuidado de su madre. En 1598 acompañó al recién nombrado rey de España Felipe III en su primera entrada pública en Madrid. Este mismo año también se hicieron capitulaciones matrimoniales entre él y su prima hermana -con quien se desposó en 1606-, Leonor de Guzmán y Silva, hija del duque de Medina Sidonia y de Ana de Silva y Mendoza -tía de Ruy Gómez, y quien daría más tarde nombre al célebre coto de Doñana(a la muerte de su tía recaería en él la primogenitura de la Casa Silva y los títulos que ello conllevaba, lo cual le produjo numerosos problemas y pleitos). En 1612 fue nombrado por Felipe III embajador extraordinario de los intereses de España en Francia. El rey, quedó tan contento de su labor en París (para concertar el doble casamiento y capitulaciones matrimoniales entre el entonces príncipe de Asturias y futuro rey Felipe IV con Isabel de Borbón, y la boda de Luis XIII de Francia con la infanta española Ana de Austria), que lo nombró a su vuelta Gentilhombre de su Cámara y Cazador Mayor de la Volatería. Aunque estuvo 
en 1623 (para hacer de mediador en el complicado pleito por la Valtellina, una estratégica zona alpina al norte de la Lombardía italiana), pues el rey Felipe IV le había nombrado embajador "extraordinario" ante la Santa Sede - ante Gregorio $\mathrm{XV}$ - a principios de año con dicha misión ${ }^{21}$. El duque, que ya contaba con cierta experiencia como diplomático, partió de Madrid el 03.03.1623 “y aunque a la ligera y en secreto, llevó más de cien personas con los criados y allegados a su persona y benignidad"22. El duque de Pastrana embarcó en Barcelona el 23.04.1623, llegando a Roma al mes siguiente; pero, durante la travesía, la flota española apresó unos navíos de una escuadra turca y capturó más de ciento cincuenta turcos, lo que le valió el recibimiento en Roma entre grandes honores. Pero no contaba con un alojamiento digno, por lo que nada más llegar, estudió la posibilidad de quedarse en el palacio del duque de Zagarolo $^{23}$ para no incomodar con su presencia al embajador permanente, el duque de Alburquerque. Pero finalmente, se alojó en el Palacio Gabriellii ${ }^{24}$, hasta que, una vez salido de Roma

muy asociado con el gobierno de Felipe III (en 1619, había acompañado también al monarca durante su jornada en Portugal), no sufrió variación alguna con el cambio de régimen producido en 1621; de hecho, en 1623 Felipe IV le encomienda un cargo de suma importancia, el de embajador extraordinario ante la Santa Sede en Roma. El duque llevó consigo a más de cien personas (con criados y allegados). Se alojó en una quinta del Papa Gregorio XV en las afueras de la ciudad. Al poco tiempo, el papa murió y ocupó su puesto el cardenal Maffeo Barberini (Urbano VIII) al que el duque había conocido tiempo atrás y con el que mantenía una buena amistad. Su labor fue muy estimada y elogiada tanto desde España como desde Roma; tanto, que el propio rey le nombró embajador ordinario o permanente. En octubre de 1626 dejó su puesto a petición propia, y el 23 de diciembre del mismo año murió en Madrid. El duque, noble de experiencia política, se destacó por su inteligencia y su gran interés por la cultura. El inventario de bienes que se hizo al poco de su muerte, destaca por incluir buen número de cuadros de pintores anónimos, así como abundantes libros (de autores como Plutarco, Ovidio, Tácito, Jenofonte, Boecio, Petrarca, Tasso, Ariosto, Serlio...), que confirman su variedad de gustos e intereses y revelan su excelente formación humanística. Vid.: SALAZAR (1685): vol. 2, 565-566.

21 GARCÍA CUETO (2007): 307-334.

22 DADSON (1987): 245-268, a partir del MS 2355, Sucesos del año 1624, fol.498r, de la Biblioteca Nacional.

23 Orazio Ludovisi $(* 1561 ; \dagger 1640)$, natural de Bolonia, era hijo del conde Pompeo Bianchini y hermano de Alessandro, luego papa Gregorio XV. En 1621 fue nombrado prefecto de las fortalezas de Perugia, Ancona, Ascoli, y gobernador del Benevento. Conde de Samoggia e Tiola (1591), se mudó a Roma con su esposa, Lavinia Albergati, con quien se casó en 1594. Luego en Bracciano, regresó a Roma en 1621, como miembro de la corte pontificia, alojándose en un primer momento en el Palacio Orsini del Campo de'Fiori. Llegaría a ser duque de Zagarolo y de Fiano, General de las Armas de la Iglesia - comandante en jefe del ejército pontificio-, y procurador de su hermano Alessandro, el papa Gregorio XV.

24 Mandado construir en el siglo XVI por el abogado Girolamo Gabrielli, en 1587 el palacio pasó a su sobrino Carlo, que en 1607 lo vendió por 20.000 escudos. Desde entonces, el Palcio Gabrielli se convirtió en sede del Seminario Romano, debido, una vez más, a su proximidad con el Colegio Romano, donde seguían sus estudios alumnos e invitados.
Alburquerque, y quedado Pastrana como embajador ordinario, este último se mudó a la residencia que había desocupado su predecesor. Luego, el asunto culminó con que el papa le alojó en una quinta privada a las afueras, y le trató con holgura. Pero Gregorio XV falleció el 08.07.1623, interrumpiendo la misión del duque, oportunidad que Ruy Gómez aprovechó para promover a un candidato favorable a los intereses que entonces tenía puestos la corona española en el norte de Italia ${ }^{25}$.

El caso es, que el duque trabó enseguida una estrecha amistad con Maffeo Barberini - por otra parte, algo menos afecto a los intereses españoles que su predecesor-, que iba a ser muy pronto elegido como nuevo obispo de Roma (el 06.08.1623), con el nombre de Urbano VIII. Curiosamente, "era grandísima la afición y amistad que le tenía [al duque de Pastrana]", llegando incluso el nuevo pontífice a escribir al arzobispo de Zaragoza y tío de Ruy Gómez, el franciscano fray Pedro González de Mendoza (*Madrid, 1570; †Sigüenza, 1639), para alabarle a su sobrino, el embajador español ${ }^{26}$.

En esta situación, por un lado provisional en el tiempo, pero por otro lado, de enormes éxitos ${ }^{27}$, el duque de Pastrana, que en virtud de su cargo y como habían hecho sus antecesores en el mismo, habría de favorecer la música en las iglesias españolas de la Ciudad Eterna, se encontró, a su llegada a Roma en 1623, con que la iglesia de Santiago de los españoles (adscrita a la Corona de Castilla) había decidido, tras acaloradas discusiones "[quitar] la música con grandes discordias, [pues] la Iglesia es de pobres y el Hospital, más"28. Seguramente, debido a esta situación, buena parte de los músicos — tanto españoles como italianos - presentes en Santiago se refugiaron en Montserrat, iglesia con la que se mantenía una relación continuada, lo que contribuyó, sin duda, a un mayor auge de esta última iglesia, "de los aragoneses", al menos, hasta la Guerra dels Segadors. Por

25 Además, y por la cordialidad entre la corona española y el gran duque de Toscana, el diplomático Pastrana fue generosamente invitado a trasladarse durante el verano a la Villa Medici durante los meses de verano, hospitalidad, la de los Medici, que Pastrana aceptaría varias veces durante su embajada: consta que viajó a Florencia en el otoño de 1624, asistiendo como invitado de los Medici a una representación teatral; y en junio de 1626, cuando se esperaba la inminente llegada de su sucesor y faltaba poco para que regresara a España, se alojaba en la Villa.

26 Biblioteca Nacional, MS 2355, fol.498v. Incluso se comentó entonces: "Y últimamente son tantas las mercedes y favores que le hace Su Santidad al Duque, que parecen increíbles, pues de su misma mesa, cuando come, o cena, dice: lleven este plato al duque de Pastrana, embajador de España; sin otros infinitos regalos y agasajos que escriben de Roma le hace Su Santidad" (Ibíd.).

27 Mientras el duque de Patrana ejercía como embajador extraordinario, el embajador ordinario (es decir, permanente) era el VII duque de Alburquerque (además de IV marqués de Cuéllar, VII conde de Huelma y de Ledesma, etc.), Francisco Fernández de la Cueva $(* 1575 ; \dagger 1637)$, que ejercería como tal hasta dicho año de 1623 .

28 A pesar de ello, el duque retuvo al maestro de capilla y organista de aquella iglesia Paolo Tarditi - decisión en la que debió pesar la belleza de sus composiciones -, que sería capaz al menos de mantener en lo sucesivo, muy dignamente, la música en Santiago. 
tanto, el puesto ocupado por Arañés en Roma iba a cobrar mayor protagonismo del que había gozado hasta entonces. Incluso las relaciones entre el papado y el arzobispado de Zaragoza, donde Arañés supuestamente se había ordenado y donde ocupaba la mitra el tío del duque de Pastrana, muy pronto dedicatario del trabajo compositivo del músico, parecían alinearse.

Pero todavía habría una carta más, esta vez del papa al monarca, en enero de 1624, donde el pontífice subrayaba también el éxito del duque de Pastrana. De resultas, esto le valdría al duque que el joven Felipe IV quisiera retenerlo en Roma, nombrándole ahora su embajador "ordinario" (es decir, permanente), y que, en mayo, incluso se le otorgara el puesto de Consejero de Estado.

Todo parecía fluir por tanto muy positivamente, pero el duque, que había estado entretanto deseoso de regresar a España (lo que había comenzado como una misión de corta duración anunciaba prolongarse), pidió en diciembre permiso para volver, que se le concedió, a expensas de que esperara hasta la llegada del nuevo embajador, el conde de Oñate ${ }^{29}$. Sin embargo, problemas provocados por la guerra en el norte de Italia impidieron su salida de Roma hasta octubre de 1626, de modo que llegó a Madrid en noviembre, aunque "tan molestado de rigurosos achaques, que ellos le quitaron la vida el día veinte y tres de diciembre del mismo año", quedando su viuda Leonor al cargo de sus asuntos.

Después de estas referencias, llega la publicación de Arañés de su conocido libro de tonos y villancicos - redactado en lengua castellana-, en Roma, en el año 1624, en donde él se declara, capellán del duque de Pastrana (a quien dedica la publicación) "y maestro de capilla", siendo este último entonces embajador del rey Felipe IV en la Corte Romana y ante la Santa Sede de Urbano VIII ${ }^{30}$.

29 Íñigo Vélez Ladrón de Guevara y Tassis (*Madrid, 02.06.1597; † Madrid, 31.10.1644), vIII conde Oñate y IV conde de Villamediana, que fue consejero de Felipe Iv, Correo Mayor de España, embajador en Viena y luego en Roma (1626-1628), y virrey de Nápoles (1648).

30 Urbano VIII [Maffeo Barberini] (*Florencia, 1568; $†$ Roma, 1664); papa (1623-1644). Urbano VIII fue célebre por su actividad diplomática, reformas eclesiásticas, obras públicas y patronazgo artístico. De familia noble, se doctoró en Derecho y empezó a trabajar en la administración de la Santa Sede en 1589. Fue delegado del papa en Francia en 1601; en 1604 arzobispo titular de Nazaret además de nuncio en Francia; en 1606, cardenal y en 1608, arzobispo de Spoleto. Al ser elegido papa, temiendo la dominación de los Habsburgo en Italia, adoptó una política de neutralidad entre el Sacro Imperio de los Habsburgo y Francia, que se había aliado con las fuerzas protestantes en la Guerra de los Treinta Años. Esta política debilitó la causa católica en Alemania. Se ocupó con intensidad de los asuntos eclesiásticos. Aprobó varias órdenes religiosas nuevas. En 1627 fundó el Colegio Urbano de Roma, dedicado a la preparación de misioneros; en 1631 autorizó la revisión del Breviario y en 1642 condenó el jansenismo. Su mayor defecto fue el nepotismo (nombramiento de familiares en cargos eclesiásticos lucrativos). Gastó enormes sumas de dinero en construcciones como el Palazzo Barberini en Roma, o la villa papal (hoy residencia veraniega del pontífice) en Castel Gandolfo y fue mecenas y amigo íntimo del pintor y
Por tanto, esta rara edición musical de Arañés (un "libro segundo" del que sólo queda un ejemplar, desconociéndose la existencia del hipotético primer libro), debió gestarse con relativa celeridad, entre la llegada del séquito del duque de Pastrana a Roma en mayo de 1623, y su publicación, el 05.09.1624. Conexiones con Roma, y con Zaragoza, la iglesia de la Corona de Aragón en la Ciudad Eterna, el embarque de Pastrana en Barcelona, etc., que evocan un ambiente con el que el propio Arañés habría estado familiarizado.

La obra en cuestión, se titula exactamente Libro Segundo de Tonos y Villancicos a una dos tres y quatro voces. Con la zifra de la Guitarra Espannola a la usanza Romana. De Ivan Arañés. En Roma, Inpresso por Juan Bautista Robleti ${ }^{31}$. Anno 1624.

Nos ofrece, entonces, prueba certera sobre su paradero, pues resulta evidente que en dicha fecha Arañés se encontraba en la Ciudad Eterna, adonde habría acompañado al duque de Pastrana, en su periplo italiano, iniciado, como va dicho, en 1623 y finalizado en 1626. (Aunque, como se ha visto, Arañés estuviera ya radicado en Roma bastante antes de la llegada del duque a la ciudad - entrado ya el año 1620, tras dejar su puesto en la catedral de Lleida el 11.05.1620 - , y regresara de la misma antes de que lo hiciera el mismo duque - pues en julio de 1626 Arañés estará ya opositando en Barcelona-).

Tiempo más tarde, al poco de que el duque de Pastrana, y con él, su séquito, regresaran ya a España (en octubre de 1626), sabemos del fallecimiento del mecenas de nuestro biografiado, acaecido, precisamente, sólo dos meses después de su regreso, en el mes de diciembre. Posiblemente, la anunciada marcha del duque de Pastrana desde hacía bastante tiempo, su residencia durante algunos meses de 1626 (ya fuera de Roma y esperando su partida) en Florencia, etc., hubieran animado entretanto a Arañés a regresar definitivamente a España, y posiblemente, a Zaragoza. Aunque tampoco hay que desdeñar la posibilidad de que Arañés nunca hubiera llegado a formar parte de una hipotética capilla musical del duque de Pastrana, sino que éste,

arquitecto italiano Gian Lorenzo Bernini. También invirtió mucho en armamento, en parte por haber emprendido una guerra contra el duque de Parma. En 1639 prohibió la esclavitud de los indígenas de Brasil, Paraguay y las Antillas. Le sucedió Inocencio X.

31 Giovanni Battista Robletti ( $f$. Roma, 1609-1650). Impresor italiano que publicó un gran número de obras musicales. Financiaba con su propio dinero cada publicación, cuando lo habitual era que lo hiciera el librero, o el propio autor o compositor. Sus primeras publicaciones datan de 1609, y entre las que se publicaron ese año, se encuentran obras de autores como A. Cifra, G. F. Anerio, G. Bartei y F. Soriano. Casi todas sus publicaciones fueron realizadas en Roma, aunque se sabe que también tuvo imprentas en Tivoli y en Rieti. Algunos trabajos de autores como F. Falconieri, S. d'India, G. Frescobaldi, J. Kapsberger, G. Asola, etc., fueron impresos por Robletti. Como otras imprentas de su tiempo, sacó a la luz algunas antologías de música que él mismo seleccionó: al menos dos de música sacra (Lilia campis en 1621 y Litanie en 1622, ambas para voces y órgano) y tres de música profana (Giardino musicale, Vezzosetti fiori y Le risonanti sfere). Su última publicación conocida fue Antiphonae et motecta de G. Giamberti, en 1650. Sus trabajos son precisos y cuidados, además de particularmente elegantes. También imprimió trabajos fuera del ámbito musical. 
movido por la tradición como embajador de apoyar a los músicos de la iglesia romana de Montserrat, hubiera accedido a recibir la dedicatoria del impreso de Arañés, que, apenas, habría sido músico (maestro de capilla y/u organista) de la mencionada iglesia italiana "de los aragoneses". El caso es que, probablemente, vuelto a España (¿Zaragoza?) habría acudido a opositar en Barcelona, sin éxito, pasando luego desde Zaragoza, y ahora ya como maestro de capilla, a la apartada y fronteriza catedral de La Seu d'Urgell, como así constará, hasta 1634, en las actas capitulares de aquella catedral, lo que veremos enseguida ${ }^{32}$.

Se encuentra, entretanto, una nueva noticia en la que no se había reparado hasta la fecha y que acabo de adelantar: al parecer, Arañés habría opositado al magisterio de capilla de la seo de Barcelona del 14 al 24.07.1626, ocasión en la que compitió con otros dos aspirantes y en la que obtuvo la plaza Marcià Albareda ${ }^{33}$. Se menciona entonces a Arañés como "canónigo de Alcañiz" (localidad de la actual provincia de Teruel cuyo archivo musical desapareció lamentablemente durante la guerra civil de 1936, aunque tal vez pueda referirse a un cargo honorífico dependiente de las catedrales de la capital aragonesa, lo que habría significado su residencia en Zaragoza y no en la mencionada localidad turolense).

Los exámenes a los que asistió Arañés en la Ciudad Condal se verificaron en concreto el martes 21.07.1626; el tribunal lo formó el sochantre Tàpies y el prior Ferran (organista entonces de la seo barcelonesa); según su dictamen, los tres opositores (de uno de los cuales se desconocen los datos) habían respondido muy bien, de manera que el magisterio podía recaer en cualquiera de los tres; y de aquella forma, se encargó al canónigo Granell que decidiera qué salario anual debería recibir el agraciado (que finalmente serían 418 libras).

De su paso por Barcelona da cuenta J. Pavia, que señala que Arañés no obtuvo el magisterio pretendido, pero que el cabildo barcelonés le pagó al día siguiente ciento cincuenta reales en concepto de ayuda de costa por el desplazamiento que había hecho (ya fuera desde Zaragoza, ya - aunque mucho más improbable - desde el mismo Alcañiz), y porque "ses portat bé" (se había portado bien) en dichas oposiciones, todo lo cual se conserva se le hizo efectivo al día siguiente, según un documento autógrafo que se conserva de Arañés en ese sentido ${ }^{34}$.

Está también probado que Arañés ocupó la plaza catalana de La Seu d'Urgell sucediendo a su anterior titular, el maestro Marcià Albareda $^{35}$ (quien, a su vez, había ocupado el cargo pirenaico en el

32 PEDRELL \& ANGLÈS (1921): 144-145.

33 PAVIA (1986): [vid. especialmente los datos ofrecidos sobre Arañés a propósito de la biografía que se ofrece del maestro de capilla de la seo barcelonesa, Marcià Albareda, en p. 203].

34 PAVIA (1986): 202-203. El documento referido se halla en $\boldsymbol{E}$-Bc, Sivella II, fol. XLIIII. Esborranys Notarials, 1626, fol. 91. Administració d'escolans, 1626-1627, fols. 13v. y 51r.

35 Marcià Albareda (*¿Vic?; fl.1616-†Vic, 1673) había sido infante de coro de la catedral de Barcelona, donde tuvo de maestro a Joan Pujol, pero lo tuvo que dejar en 1616 al perder la voz de tiple. En 1619 fue nombrado maestro de capilla en la iglesia parroquial de San Justo y Pastor de Barcelona. Posteriormente, se hizo cargo del magisterio en La período de 1622 a 1626, cuando pasó a ocupar el magisterio de la catedral de Barcelona, sustituyendo a Joan Pujol ${ }^{36}$. A partir de ahí, le encontraremos en La Seu d'Urgell entre 1627 y 1634.

Parece que el cabildo de La Seu d'Urgell envió a buscarle como maestro hasta Zaragoza — su ciudad natal — , donde al parecer habría estado residiendo al regresar de Roma, como así consta en el libro Rationale 1608-1626 (el cual se extiende más allá en el tiempo de lo que indica su título), mediante un asiento documental del 26.02.1627, en el que se acuerda que se paguen veinticinco libras barcelonesas al ministril (bajón de la capilla) mosén Juan Menalt "per los gastos d'anar a sercar mestre de Capella y cantors a Çaragoça".

Seu d'Urgell, en concreto del 08.01.1622 al 24.07.1626, de donde pasó a ocupar el cargo en la seo de Barcelona mediante oposición, sustituyendo a Joan Pujol, del que fue discípulo. En estas oposiciones tuvo como oponente a nuestro biografiado Juan Arañés, a la sazón canónigo de Alcañiz. En aquella ocasión, de los tres opositores a la vacante, el dictamen del tribunal declaraba que cualquiera de los aspirantes pudo haber merecido la plaza. Parece, pues, que la elección se hubiera encaminado a elegir un candidato joven y prometedor, y en cierto modo "de la casa" (téngase en cuenta que por aquellas fechas Arañés sería un hombre ya maduro y posiblemente con una trayectoria algo inestable -había ocupado diversos magisterios de capilla Tortosa, Lleida, La Seu d'Urgell, Tortosa de nuevo, Roma, viajes y familia que parecían ligarle a Zaragoza...-). Albareda estuvo al frente de esta capilla alrededor de cuarenta años, siéndole concedida la jubilación a petición propia a mediados de 1664 . Fue entonces relevado en el puesto por Miguel Selma. Llamativamente, en 1640 dirigió una obra para ocho coros (muy posiblemente compuesta por él), con la intervención de ocho capillas de la ciudad, que fue un testimonio fuera de lo común en el contexto de la práctica policoral de la Cataluña del barroco. Así, compuso numerosas obras policorales que todavía se conservan, entre misas, antífonas o el villancico al Santísimo Sacramento Hoy deste pan consagrado.

36 Joan Pujol (*Mataró, 1570; †Barcelona, 1626). Formado en Barcelona bajo la tutela de J. Andreu Vilanova (maestro de capilla de dicha catedral, del que más tarde sería su ayudante). Fue maestro de capilla en la catedral de Tarragona y posteriormente, en 1595, ganó las oposiciones para maestro de capilla de El Pilar de Zaragoza. Aquí se ordenó sacerdote y estuvo cerca de diecisiete años, donde tuvo discípulos como Diego Pontac (que, a su vez, llegaría a teniente de maestro en la Real Capilla de Felipe IV). En 1612 regresó a la seo de Barcelona como maestro de capilla, sustituyendo a Jaume A. Tàpies. Obtuvo la plaza y allí formó alumnos como Josep Reig, Marcià Albareda, y otros. Fue responsable también de la capilla musical de San Jorge de la Generalitat. El inventario de sus bienes incluía libros de canto propios y de autores como Palestrina, Morales, Guerrero o Victoria, probablemente utilizados como modelos para el estudio. Su estilo compositivo, a caballo entre un último renacimiento y el primer barroco, muestra un profundo conocimiento de los polifonistas hispánicos, así como del stile moderno y los autores italianos, junto a la bicoralidad y un empleo del villancico - especialmente del Corpus y de Navidad- conducente hacia una cierta teatralización y formas de expresión (en la línea de Capitán o Comes). Se conservan numerosas obras de su composición, siempre manuscritas, especialmente en Zaragoza y la barcelonesa Biblioteca de Cataluña. Destacó particularmente en el género litúrgico (misas, pasiones, salmos, motetes, lamentaciones, magníficat, antífonas, himnos, letanías...), llegando a convertirse en modelo a seguir para la polifonía de facistol. Compuso un centenar de villancicos -sólo una veintena conservados-, además de tonos a lo humano y diversas letras, copiadas en diversos cancioneros poético-musicales de la época (el de Múnich, los Romances y letras de a tres voces, el de Olot, el de la Casanatense de Roma...). 


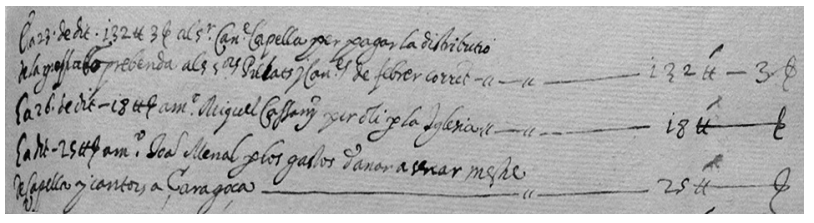

Figura 4. El cabildo catedral de La Seu d'Urgell envía a su bajonista Juan Menalt a buscar maestro de capilla (Arañés) y cantores a Zaragoza (26.02.1627)

Hay que tener en cuenta que Arañés, como va dicho, había coincidido pocos meses antes en las oposiciones al magisterio de capilla de la catedral de Barcelona con Marcià Albareda, último maestro en el Alto Urgel (donde consta al menos en nómina hasta mayo de 1626) quien, precisamente, obtuvo enseguida la plaza de la Ciudad Condal. Tal vez, el conocimiento personal de Arañés y Albareda hubiera influido en que el cabildo pirenaico, ahora con su puesto de maestro vacante, fuera a buscar un candidato precisamente a Zaragoza, acaso advertido de que allí estaba Arañés, afamado por haber estado recientemente en Roma y haber publicado sus obras, y en expectativa de destino. Sea como fuere, el caso es que seguramente, tras contactar con Menalt en la capital aragonesa, Arañés se encaminó hacia La Seu d'Urgell, pues el 22.04.1627 se le cita ya por primera vez en las actas capitulares de la seo pirenaica como su nuevo maestro de capilla.

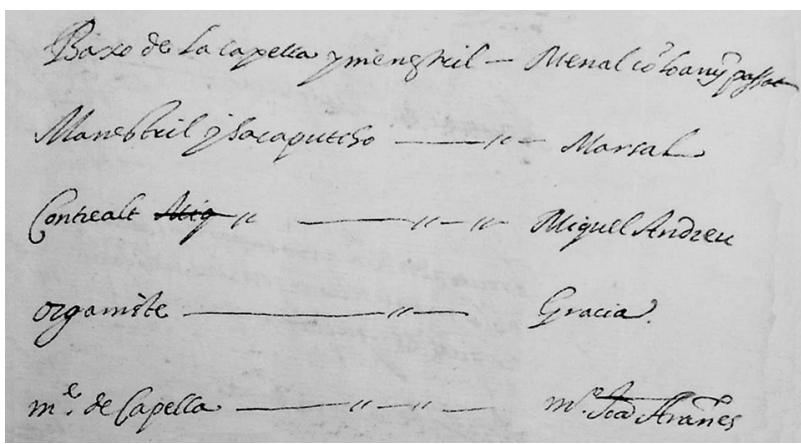

Figura 5. Primera mención de Juan Arañés como maestro de capilla en La Seu d'Urgell (Nota officialium, 22.04.1627)

Y a los pocos días, con motivo de las celebraciones de la Semana Santa, el cabildo recuerda que ha de ser Arañés quien seleccione quiénes deberán ser los que canten el Passio, y encargarse también de recibir y repartir entre él mismo y los cantores agraciados las siete libras barcelonesas estipuladas a tal efecto por la realización de dicho trabajo.

Ese mismo año de 1627 (en julio, agosto y noviembre) constan asimismo documentalmente varios pagos al maestro Arañés en La Seu d'Urgell a cuenta de los niños de coro o "preveners", pagos cotidianos y aconteceres habituales relativos a la capilla regida por nuestro biografiado, sin revestir mayor interés, que se repetirán en los años sucesivos de su estancia en la ciudad pirenaica. Como nota curiosa, Arañés recibe también un pago en especie, en este caso, en trigo, como era relativamente frecuente en la época a la hora de abonar los salarios de los músicos (en ocasiones, incluso identificados como racioneros "de pan y vino" por esta misma razón).

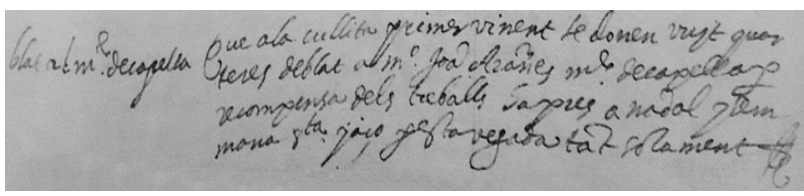

Figura 6. Pago en trigo (ocho "quarteres") como recompensa o gratificación puntual a Arañés, por su buen trabajo, durante las navidades y Semana Santa pasadas (E-SUe, actas capitulares, 27.04.1630)

A partir de 1631, y hasta mayo de 1634, se registra periódicamente en las resoluciones capitulares (Nomina officialium) la obligación del maestro Arañés de enseñar canto durante una hora diaria en el coro.

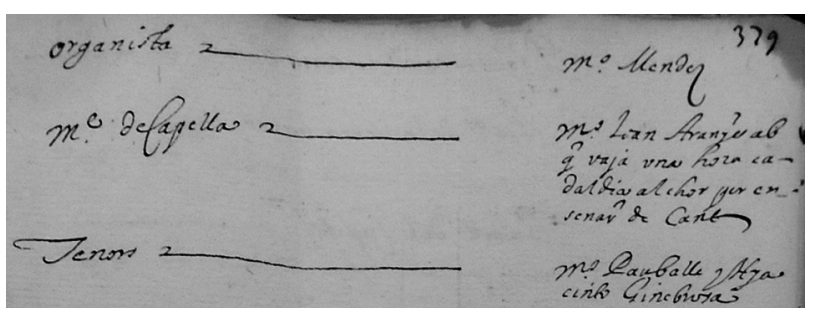

Figura 7. Recordatorio al maestro de capilla (Arañés) de acudir una hora diaria al coro para dar clase de canto

La última vez que aparece citado en la nómina de oficiales, entre la que se encuentran los músicos en plantilla de la capilla catedralicia, es el 04.05.1634. El 10.11.1634 el capítulo urgelés buscaba ya nuevo maestro de capilla, como se desprende del hecho de que se manda y acuerda que los niños de coro o "preveners" tenían que vivir en casa del corneta "hasta que la iglesia tenga maestro de capilla", lo que no iba a ocurrir hasta el 23.03.1635, con la llegada del nuevo maestro, Jaime Vidal ${ }^{37}$.

Entre 1634 y 1649 ya no hay más noticias de él en La Seu d'Urgell, pues se le localiza entonces nuevamente en Tortosa. De hecho, en este período, y tras el magisterio de Jaime Vidal

37 Jaume Vidal (*Sant Feliu de Llobregat, 1607; †Montserrat, 1689), se había formado como niño cantor en la escolanía de Montserrat, con los monjes Bernat Barecha y Joan March. Compositor y monje benedictino en la célebre abadía catalana, ocupó, a lo largo de su vida, diferentes cargos importantes, como por ejemplo, abad del monasterio de Sant Genís de les Fonts, o cantor mayor de Montserrat. Catalogó el archivo del monasterio de Ripoll y Tarragona. Dejó algunas obras músico-religiosas que se conservan en su mayoría en la Biblioteca de Catalunya (misas a 5, 6, 8 y 15 voces, la lamentación Cómo está la ciudad de la gran Jerusalén a 4 voces, salmos, el villancico al Santísimo Fugitivo paxarillo que por el aire te vas a 4 voces, etc.), muchas de ellas hoy lamentablemente incompletas. Parece probado que se trata del mismo Jaume Vidal que ocupó la dirección de la capilla musical de la Seu d'Urgell entre 1635 y 1637, y nuevamente, de 1650 a 1653. 
en la localidad del Pirineo, ocuparán su anterior cargo en La Seu d'Urgell los maestros Miquel Andreu ${ }^{38}$ y Miquel Casals ${ }^{39}$.

En el mes de julio de 1634, el cabildo catedralicio de Tortosa (Tarragona), sabedor de que su maestro titular, Antoni Bru, había salido con permiso de la ciudad (se encontraba en Balaguer, Lleida) y no llevaba intención de regresar, envió a buscar a Juan Arañés a La Seu d'Urgell para ofrecerle su magisterio de capilla.

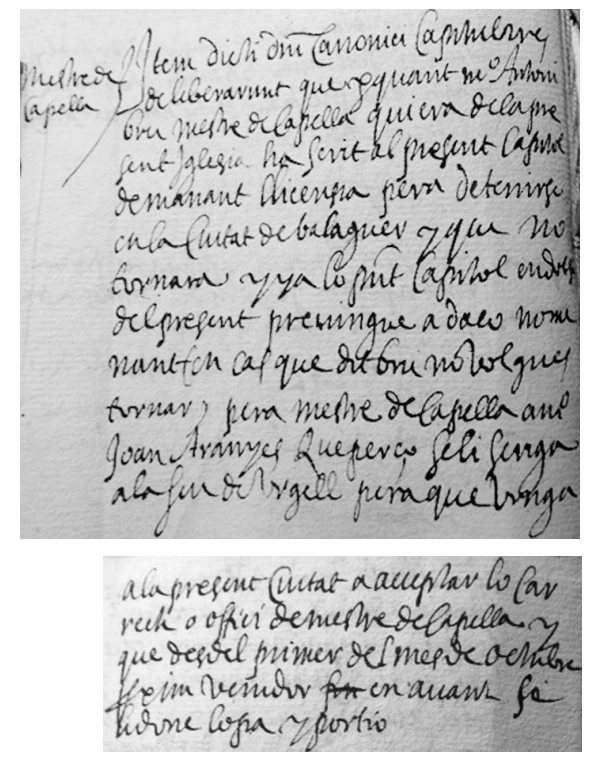

Figura 8. Noticia en el cabildo de Tortosa de que su maestro, Antoni Bru, no iba a volver, y orden para ir a buscar a Juan Arañés, "para que venga a la presente ciudad a aceptar el cargo u oficio de maestro de capilla" (E-TO, actas capitulares, 1634, s.f.)

Como se ha dicho, Arañés ya había sido maestro de capilla en Tortosa anteriormente (1604-1614), de donde se desprende la buena fama que habría dejado por tierras del Ebro, aun transcurridas nada menos que dos décadas. Pero seguramente, habría llegado el eco y prestigio derivado de su estancia en Roma, su publicación de com-

38 Miquel Andreu (fl.1612-1646) fue contralto de la capilla musical de la Seu d'Urgell entre 1612 y 1637 . Fue nombrado maestro de capilla en dicha catedral en 1638, permaneciendo en el puesto hasta 1646. Se conserva un manuscrito suyo de un salmo Dixit Dominus; y se conoce también un motete (que en realidad, se trata del quinto versículo del salmo Dixit Dominus) Juravit Dominus, a 4 voces, acaso procedente del salmo citado [cfr.: PEDRELL \& ANGLÈS (1921): 145-147].

39 Se sabe de la actividad del compositor catalán Miquel Casals (fl.1647-1648) durante la segunda mitad del siglo XVII. Consta como maestro de capilla de la catedral de La Seu d'Urgell entre 1647 y 1648. En la Biblioteca de Catalunya se conserva el cántico Magnificat, la antífona mariana Alma redemptoris Mater y el salmo Cum invocarem, todos ellos escritos para ocho voces en dos coros. posiciones musicales, etc. Y tal vez, después de varios años ejerciendo su actividad en La Seu d'Urgell, el cabildo tortosino habría podido sondear o incluso tal vez saber de su intención de salir de las duras tierras pirenaicas, por lo que se dispuso a ir a por él. Tampoco hay que perder de vista el hecho de que en Tortosa residía su hermana, Magdalena, seguramente un foco de noticias en la ciudad tarraconense sobre su hermano, noticias que seguramente habrían sido muy bien consideradas durante y a partir de su etapa italiana.

-[Fol. s/n v.:] [Margen:] "Mestre de / Capella”. [Contenido:] "Item dicti dni Canonici Capitulares / deliberarunt que per quant m.o Antoni / Bru mestre de capella qui era de la pre / sent Iglesia ha servit al present Capitol / demanant llicensia pera detenirse / en la ciutat de Balaguer y que no / tornara y ya lo pnt. Capitol en dret / del present previngue ad aço nome / nant (en cas que dit Bru no volgues / tornar) pera mestre de capella a m.o / Joan Aranyes que per aço se li serga / a la Seu de Urgell pera que vinga / [Fol. s/n r.:] a la present ciutat a acceptar lo car / rech o offici de mestre de capella y / que desde el primer del mes de octubre / en per venidor en avant se / li done lo pa y portio".

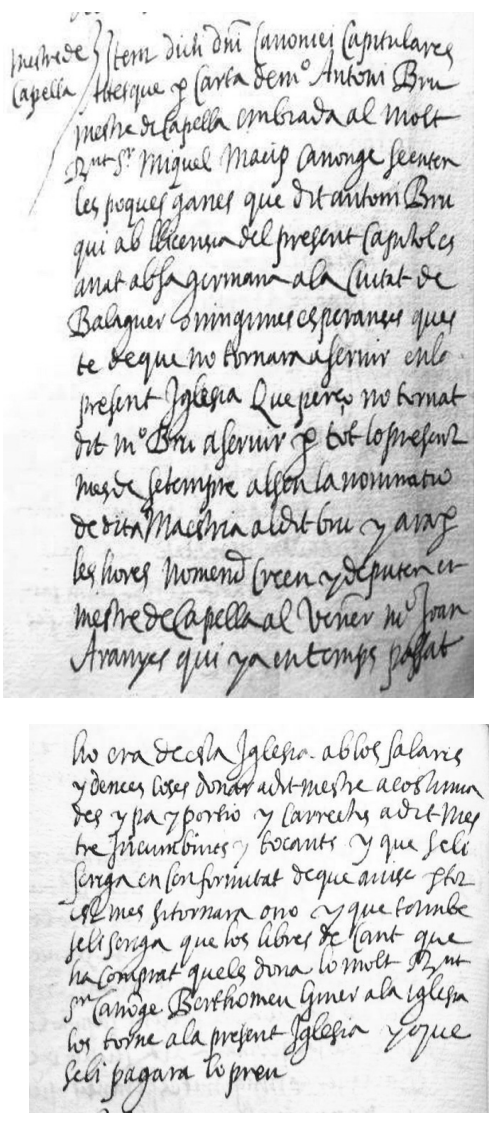

Figura 9. Nombramiento a Juan Arañés como nuevo maestro de capilla de la catedral de Tortosa (por segunda vez), al comprobar que Bru no quería volver (setembre 1634) 
-[Fol. s/n r.:] [Margen:] "Mestre de / Capella". [Contenido:] "Item dicti dni Canonici Capitulares / Attes que per carta de m.o Antoni Bru / mestre de capella embiada al molt / R. ${ }^{\text {nt }} \mathrm{S}$. Miquel Macip canonge se enten / les poques ganes que dit Antoni Bru / qui ab llicensia del present Capitol es / anat ab sa germana a la ciutat de / Balaguer o ningunes esperançes ques / te de que no tornara a seruir en la / prensent iglesia Que per ço, no tornat / dit m.o Bru a seruir per tot lo present / mes de setembre alsen la nominatio / de dita maestria al dit Bru y ara per / les hores nomenen creen y deputen en / mestre de capella al vener m.o Joan / Aranyes qui ya en temps passat / [Fol. s/n v.:] ho era desta Iglesia ab los salaris / y demes coses donar a dit mestre acostuma / des y pa y porsio y carrechs a dit mes / tre incumbints y tocants y que se li / serga en conformitat de que auise per tot / el mes si tornara o no y que tambe / se li serga que los libres de Cant que / ha comprat quels dona lo

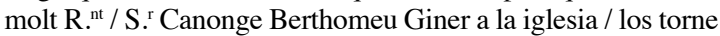
a la present Iglesia y que / se li pagara lo preu". (17.09.1634).

Al poco tiempo, y ya nombrado y residiendo en la ciudad tarraconense, el capítulo tortosino acuerda que se le ajusten y regularicen las cuentas, seguramente con carácter extraordinario, ya que cobraba más en La Seu d'Urgell que en Tortosa.

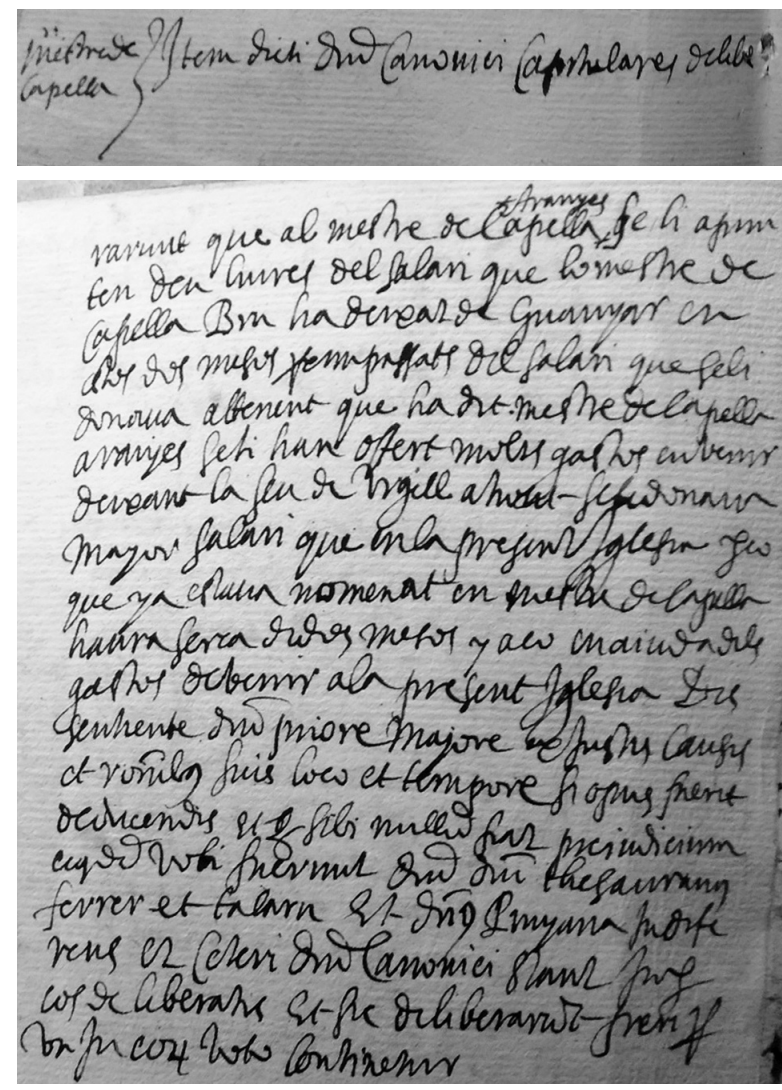

Figura 10. Ajuste económico al maestro de capilla Arañés al poco de su llegada $(\boldsymbol{E}-T O$, actas capitulares, 1634, s.f.)
-[Fol. s/n v.:] [Margen:] "Mestre de / capella”. [Contenido:] "Item dicti dni Canonici Capitulares delibe / [Fol. s/n r.:] rarunt que al mestre de capella +Aranyes+ se li apun / ten deu lliures del salari que lo mestre de / capella Bru ha deixat de guanyar en / los dos mesos perem passats del salari que se li / donava attenent que ha dit mestre de la capella / aranyes se li han offert molts gastos en venir / deixant la Seu de Urgell a hont se li donava / major salari que en la present Iglesia per ço / que ya estaba nomenat en mestre de capella / haura cerca de dos mesos y aco en aiuda dels / gastos de venir a la present Iglesia [...]".

Durante el período 1634-1648, pues, estuvo en Tortosa. Las informaciones sobre su actividad en este período se refieren a hechos cotidianos en la práctica profesional de cualquier capilla de música catedralicia (préstamo del órgano portativo de la catedral a diversas iglesias y conventos de la ciudad, pagos a músicos, licencias...) $)^{40}$.

Una de las pocas entradas documentales que atestigua que Arañés estaba residiendo en la ciudad, data del 16.01.1646, cuando se le menciona expresamente a propósito de un nuevo pago:

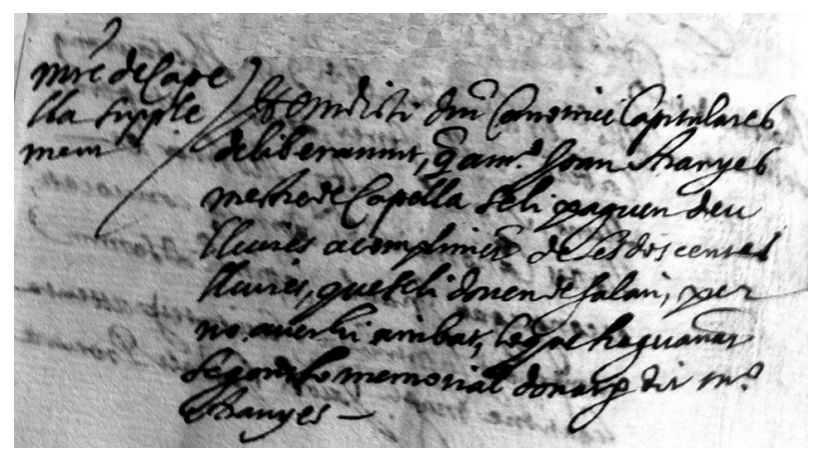

Figura 11. Concesión capitular de un pago solicitado previamente mediante un memorial por mosén Juan Arañés, maestro de capilla $(\boldsymbol{E}-T O$, actas capitulares, 16.01.1646)

No obstante, y del mismo año 1646, he podido localizar un nuevo documento que liga a Arañés con Tortosa. Se trata de un primer testamento de la hermana de nuestro músico, dado el 27.01.1646, y gravemente enferma ${ }^{41}$. En él, aunque quedara revocado por un segundo testamento a los pocos días (el 06.02.1646), se estipulaban las últimas voluntades de Magdalena Arañés Sallén, entonces esposa en segundas nupcias del farmacéutico o boticario Martí de Monte, residente en Tortosa. Finalmente, y como se verá, Magdalena Arañés moriría al poco tiempo (el 12.02.1646).

40 En 1638 Arañés pidió al cabildo un aumento de salario, que se le concedió, de modo que es seguro que residió varios años en Tortosa durante ésta su segunda etapa de magisterio de capilla en la ciudad.

41 Archivo Histórico Comarcal de "les Terres de l'Ebre". Caja: Tor-689 / A. H. P. [Archivo Histórico de Protocolos] / TARRagona / N 1996 y 1997. 
Curiosamente, la primera versión testamentaria de Magdalena Arañés, trataba a su hermano como "molt amat" (es decir, "muy querido"), dejándole como usufructuario de todos sus bienes, lo que cambiaría a los pocos días. Se daba cuenta ahí también de que era esposa en segundas nupcias de Martí de Monte, boticario de Tortosa, y en primeras nupcias (es decir, que entretanto, habría enviudado, sin que se mencione descendencia alguna de ninguno de ambos matrimonios), de Jeroni Verdejo, notario de Tortosa. Consta además que era hija de Joan Arañés, ciudadano de Zaragoza y de Mariana Sallén, entonces ya difuntos, con lo que se confirma, una vez más, el "definitivo" origen zaragozano de nuestro biografiado y su familia.

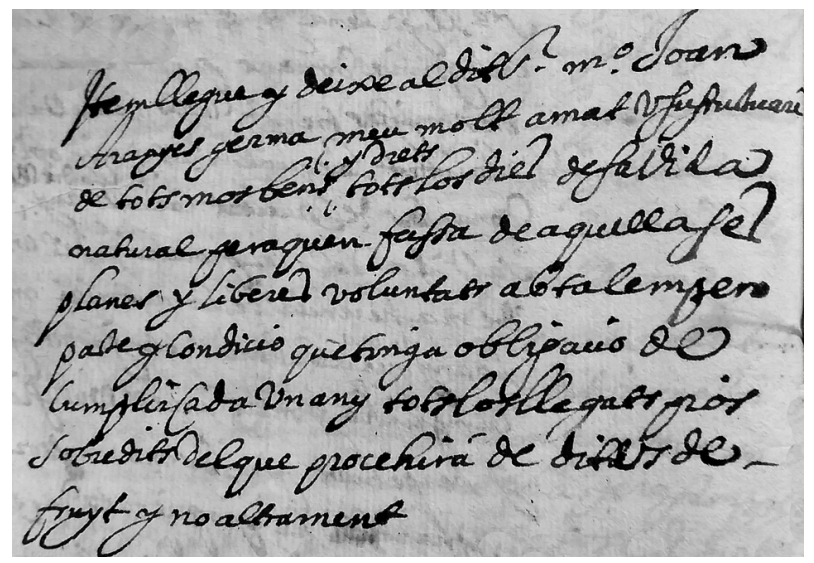

Figura 12. Fragmento de la primera versión - luego revocada - del testamento de Magdalena Arañés, en donde dejaba a su hermano el usufructo de todos sus bienes

Por su parte, la segunda y definitiva versión del testamento de Magdalena Arañés, recogido por el notario Pere Maridá, firmado de su propia mano, y en el que actuaron como testigos Francesc García, sastre, y Joan Prats, payés de Tortosa, la hermana de nuestro músico aclara que se encontraba en ese momento "detinguda en lo llit de malaltia corporal de la qual teme morir" (es decir, "detenida en la cama de enfermedad corporal, de la cual teme morir"). En ese momento, eligió como albaceas a tres personas, a saber: 1.- "al p[rese]nt Pare Prior del monastir y convent de ntra. S. ${ }^{\text {ra }}$ del miracle del orde de ntra. S. ${ }^{\text {ra }}$ del Carme de descalços de la p[rese]nt ciutat" (o sea, "al presente padre prior del monasterio y convento de Nuestra Señora del Milagro, de la orden de Nuestra Señora del Carmen, de descalzos de la presente ciudad", el reverendo padre hermano Andrés de la Cruz; 2.- a mosén Juan Arañés, maestro de capilla de Tortosa, su hermano; y 3.- a Pere Maridá, notario de Tortosa (y el mismo que registra el presente testamento).

En el contenido testamentario definitivo de Magdalena Arañés, llama la atención la parte importantísima que supone su encargo de numerosas misas por su alma, en diversas iglesias y capillas de la ciudad de Tortosa, muestra todo ello de su religiosidad y devoción. Pide al mismo tiempo ser enterrada en uno de los vasos de la capilla de Ntra. Sra. del Rosario del monasterio de San Francisco, de la orden de predicadores, situado "fuera y cerca de los muros" de la ciudad de Tortosa. Y deja 50 libras barcelonesas a su esposo Martí de Monte, 100 libras a su joven sobrina (de su primer matrimonio) Paula Verdejo - para que pueda casarse o tomar hábito en un convento según sea su deseo - , y 200 libras a su hermano Juan Arañés.

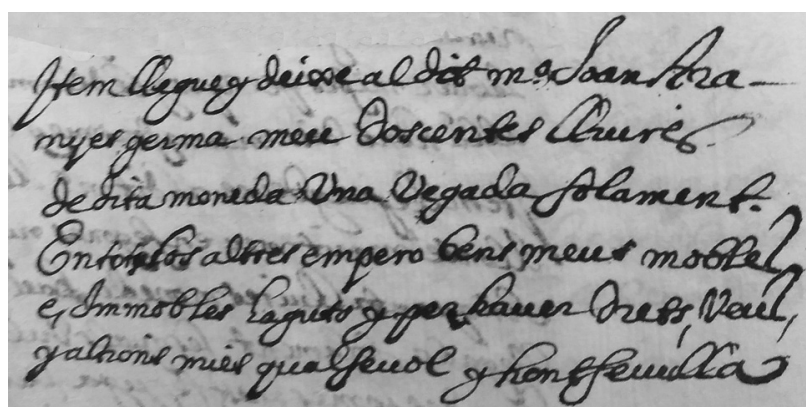

Figura 13. Herencia testamentaria dejada a Juan Arañés, por su hermana Magdalena. Segundo y definitivo testamento

de Magdalena (06.02.1646), con la noticia de su óbito (el 12.02.1646) y una incorporación post-mortem

Como colofón a este testamento, se hallan sendas adiciones anotadas ya después del fallecimiento de Magdalena Arañés, con la aceptación por un lado de Juan Arañés y Pere Maridá como albaceas testamentarios (15.02.1646), siendo testigos Francisco Simeón Minguella, mercader, y Mateo Casals, notario público de la ciudad de Tortosa, y por otro lado, con la aceptación en escrito aparte (15.04.1646), del prior Andrés de la Cruz, siendo sus testigos Francisco Pallarés y Jacinto Labau. Datos, todos ellos, que certifican la presencia de Juan Arañés como maestro de capilla en Tortosa en 1646.

Al poco (03.08.1647), Arañés participaba ya, como miembro del tribunal que había de juzgar unas oposiciones a la comensalía de San Miguel, llamada "del maestro de canto". Actuaba como examinador, junto al organista, José López; y se presentaron como opositores Maximiano Fraile, sacerdote, de Castellón de la Plana, y Antonio Miralles, clérigo de Vinaroz: 
[Margen:] Relatio examinis super commensalia cantus. [Contenido:] Item, coram dictis domini canonicis capitularibus et in capitulo comparuerunt venerabilis Joannes Arañes, // presbiter, magister cantus capellae presentis ecclesiae, et Josephus Lopez, presbiter, commensalis organi dictae sedis, examinatores alias electi ad examinandum oppositores vacationi commensaliae cantus presentis ecclesiae ad presentem vaccanti per mortem venerabilis Francisci Patus, quondam illius ultimi commensalis et possessoris, qui sunt Antonius Miralles, clericus de Vinaros, et Maximianus Frayle, presbiter Castilionis Planiciei, et retulerunt et renuntiarunt se examinasse dictos Miralles et Frayle ad dictas commensalias obtinendam et invenisse habiliorem dictum Frayle tam in voce quam in cantu.

[Margen:] Que $\cdot$ s donen 3 lliures a Miralles per sos treballs. [Contenido:] Item, dicti domini canonici capitulares deliberarunt se donen a mossèn Antoni Miralles, clergue // de Vinaròs trenta reals per los treballs [que] ha tengut de venir-se a opposar y subir examen.

[Margen:] Nominatio, provisio et collatio commensaliae Sancti Michaelis, vulgo dicta del mestre de cant Maximiano Frayle.

[Contenido:] Item dicti domini canonici capitulares, attendentes vitae ac morum honestatem et in cantu habilitatem aliaque laudabilia probitatis et virtutum merita super quibus venerabilis Maximianus Frayle, presbiter oppidi Castillionis Planiciae diocesis Dertusensis apud ipsos fidedigno et publico testimonio commendatus existit, attendentes etiam officium magistri cantus presentis ecclesiae et commensaliam Sancti Michaelis eiusdem ecclesiae dicto officio magistri cantus unitam in presentiarum vacare per mortem seu decessum venerabilis Francisci Patus, quondam ipsius officii magistri cantus et commensaliae eidem unitae, ultimi et immediati possessoris, quarum electio, collatio, provisio et omnimoda dispositio juxta constitutionem Pape Benedicti in-//cipientem Ut igitus degentes [...] domini et constitutiones et consuetudines dictae sedis et alias ad dictum capitulum canonicorum pleno jure pertinet et spectat in sequendo igitur praefatas laudabiles constitutiones et consuetudines presentis Dertusensis ecclesia, usum , stillum et practicam ac vestigia praedecessorum suorum ad dictum officium magistri cantus sicut $[. .$.$] vaccanti [. .$.$] venerabilem Maximianum$ Frayle, presbiterum tanquam habilem et idoneum ad dictum officium magistri cantus obtinendum nominarunt et elegerunt sub pacto tamen e conditione quod teneatur reverendum dominum episcopum docere cantum et tres servitores, item quemlibet dominum canonicum et unum servitorem, et alia facere quae praedecessores sui in dicto officio magistri cantus et commensalia eidem annexa juxta constitutiones et consuetudines // dictae sedis consueverunt facere. Et dicta nominatione <et electione> facta praefatam commensaliam Sancti Michaelis praedicto officio magistri cantus unitam eidem Maximiano Frayle contulerunt et assignarunt et ipsum in dicta commensalia canonice instituerunt [siguen formulismos hasta el final].
[Margen:] Relato del examen sobre la comensalía de canto. [Contenido:] Ítem, delante de los dichos señores canónigos capitulares y en capítulo comparecieron los venerables Juan Arañés, // sacerdote, maestro de canto de la capilla de la presente iglesia, y Josep López, sacerdote, comensal del órgano de dicha seo, examinadores o elegidos para examinar a los opositores de la comensalía de canto vacante de la presente iglesia, actualmente vacante por la muerte del venerable Francesc Pato [?], antes su último comensal i poseedor, los cuales [opositores] son Antoni Miralles, clérigo de Vinaròs, y Maximià Frayle, sacerdote de Castelló de la Plana, y relataron y declararon que habían examinado a los dichos Miralles y Frayle a obtener dichas comensalías, y que encontraron más hábil al dicho Frayle tanto en voz como en canto.

[Margen:] Que se paguen 3 libras a Miralles por sus trabajos. [Contenido:] Item, dicti domini canonici capitulares deliberarunt se paguen a mosén Antoni Miralles, clérigo // de Vinaròs treinta reales por los trabajos [que] ha tenido por venir a opositar y subir examen.

[Margen:] Nombramiento, provisión y colación de la comensalía de Sant Miquel, vulgarmente dicha del maestro de canto a Maximià Frayle.

[Contenido:] Ítem, los dichos señores canónigos capitulares, considerando la honestidad de vida y costumbre, la habilidad en el canto y otros méritos loables de rectitud i virtudes sobre los cuales el venerable Maximià Frayle, sacerdote de la población de Castelló de la Plana, diócesis de Tortosa, delante los mismos [capitulares] existe estimado en fidedigno y publico testimonio; considerando, además, que el oficio de maestro de canto de la presente iglesia y comensalía de Sant Miquel de la misma iglesia, unida a dicho oficio de maestro de canto, vacante por muerte o traspaso del venerable Francesc Patus (?), antes último e inmediato poseedor del mismo oficio de maestro de canto y de la comensalía al mismo [oficio] unida; porque la elección, colación, provisión y de todas formas disposición según la constitución del Papa Benet que comienza Ut igitus degentes [...] domini y las constituciones de dicha seo y otras que a dicho capítulo de canónigos de pleno derecho pertenece y contempla, siguiendo por tanto las anteriormente dichas loables constituciones y costumbres de la presente iglesia de Tortosa al uso, estilo y práctica así como las huellas de sus antecesores, como sea vacante el oficio de maestro de canto nombraron y elegir en dicho oficio Maximià Frayle, sacerdote, como hábil e idóneo para obtener dicho oficio de maestro de canto, bajo el pacto, pero, y condición que deba enseñar al reverendo señor obispo y a tres servidores [suyos], así como a cualquier señor canónigo y un servidor [suyo], y hacer cualquier otra cosa que los predecesores en su oficio de maestro de canto y la comensalía anexa, según constituciones de dicha seo, acostumbraran hacer. Y realizado dicho nombramiento $<\mathrm{y}$ elección $>$, confirieron y asignaron al mismo Maximià Frayle la mencionada comensalía de Sant Miquel unida al desuso de dicho oficio de maestro de canto, y lo instituyeron canónicamente en dicha comensalía [...]

Transcripción del acta capitular en la que consta la participación de Juan Arañés, como juez del tribunal de oposiciones a la comensalía "del maestro de canto" $"$ 
Muy posiblemente, la marcha de Tortosa de Arañés tuviera que ver con la suspensión de la capilla de música, decretada el 25.08.1648, y forzada por la pésima e insostenible situación económica de la catedral, como así consta por sus actas capitulares:

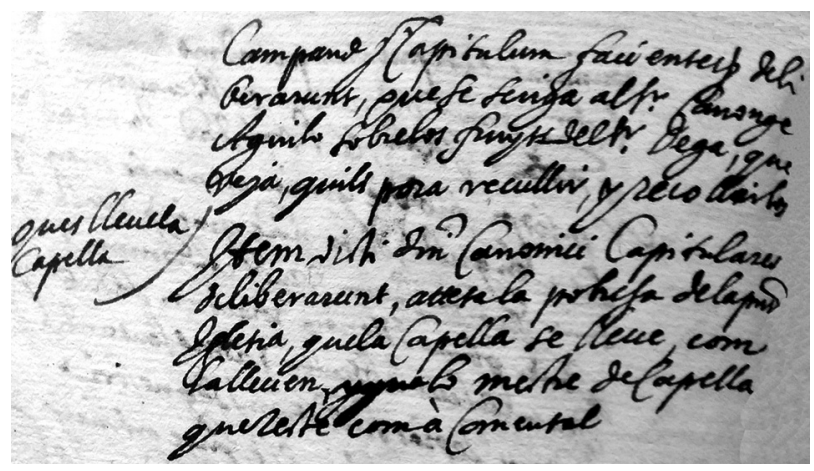

Figura 14. Orden de suprimir la capilla de música de la catedral de Tortosa (25.08.1648)

$\boldsymbol{E}$-TO, actas capitulares, 25.08.1648: [Fol.r. s/n:] "Die martis Xxv mensis Augustis / anno dni MDCXXXXVIII". [Fol. v. s/n:] [...] [Margen:] "Ques lleve la / capella". [Contenido:] "Item dicti dni Canonici Capitulares deliberarunt, attesa la pobresa de la pnt. / Iglesia, que la Capella se lleve, com / la lleven, y que lo mestre de Capella / que reste com a comensal".

Por lo tanto, ha de verse la situación financiera de la seo tortosina como absolutamente precaria: ya cuando se fue a buscar al maestro Arañés hasta La Seu d'Urgell se le ofreció un salario menor del que allí tenía; pero, lógicamente, una catedral no podía quedar privada de culto diario, para lo que debía mantener, hasta donde esto fuera posible, una mínima capilla de música que sirviera eficazmente a la dignidad y solemnización de los oficios. Finalmente, hubo de forzarse a Arañés a quedar únicamente como comensal, merma de salario y de su actividad profesional especializada, que seguramente le habría animado a buscar un mejor destino a la mayor brevedad.

Pero tampoco hay que perder de vista un detalle en el que no se había reparado hasta ahora: precisamente, en 1648, llegó la peste negra a la ciudad de Tortosa, circunstancia que no se menciona en esta documentación capitular concreta, pero que, muy posiblemente, hubiera tenido no poco que ver en el hecho de que el capítulo tortosino decretara la supresión de su capilla de música.

Y además, la ciudad se vio sitiada ese mismo año, a partir del mes de junio, por tropas franco-catalanas (siete mil soldados distribuidos en catorce regimientos $)^{43}$, en el marco de la con-

43 La conquista de la ciudad por tropas galas y catalanas tuvo lugar entre el 10 de junio y el 12 de julio. Los franceses, bajo el mando de Ferdinand de Marchin, aportaron a la toma de la ciudad tres mil tienda secesionista catalana (la "Guerra dels Segadors"); en el mes de noviembre, la flota francesa sitiaba la ciudad por mar, acudiendo en su socorro tropas reclutadas en Zaragoza y barcos leales a Felipe IV.

Fue así como parece que Arañés regresó, de nuevo, en 1649, y seguramente empujado a ello por las condiciones cada vez más adversas de la ciudad surcatalana, a su anterior desempeño como maestro de capilla de la catedral de La Seu d'Urgell. Pero esta vez iba a ocupar este cargo solamente por unos meses, pues en noviembre de ese mismo año se acordaba nuevamente poner edictos para cubrir el magisterio de capilla, síntoma evidente de que éste había quedado otra vez vacante.

Y entretanto, y aun a pesar de las desastrosas condiciones con que había de lidiar la capilla de música por esas fechas (peste, sitio y toma violenta de la ciudad por las tropas, etc.), todavía se proseguía con una actividad aparentemente normal, pues la documentación refleja pagos puntuales a algunos músicos (como el registrado el 03.12.1647, de dos libras barcelonesas, "a un soldado borgoñón" apellidado Bausan).

La cuestión es que, en 1649, Arañés estaba ya nuevamente en La Seu d'Urgell, parece claro que sí estuvo allí, a juzgar por el capítulo pascual de dicho año, registrado en las actas capitulares de dicha localidad pirenaica, que no me ha sido posible consultar, pero que recogen F. Pedrell y H. Anglés en su conocido estudio sobre Joan Brudieu ${ }^{44}$.

A partir de ahí, se pierde definitivamente su rastro, por lo que bien se puede suponer que hubiera fallecido por entonces (es decir, antes de noviembre de 1649, cuando debía de contar ya con una edad muy avanzada para su época - repárese en su nacimiento en la década de 1580-). Le sustituyó allí el mismo Jaime Vidal (que aparece ya en el capítulo pascual de 1650 y hasta 1653), quedando probado, no obstante, que Pau [o Pablo] Marqués ${ }^{45}$ ocuparía ya este puesto a partir de 1655 .

soldados de caballería y 20 cañones. Y los catalanes, luchaban bajo el mando del mariscal de Schomberg, participando también algunas unidades de caballería ligera. Entre los comandantes catalanes estaban Josep Tort, Francesc Cescarós, Josep d'Ardena y Josep Margarit i de Biure. Finalmente, el 12.07.1648, la artillería catalano-francesa logró abrir brecha en la muralla, introduciéndose en la ciudad, mientras las tropas de Felipe Iv se refugiaban en el castillo y la población civil lo hacía en las iglesias. El general Marchin prohibió el saqueo, pero sin éxito: se saquearon conventos e iglesias y no se respetó a las mujeres, ni siquiera a las religiosas. Fue la última conquista francesa en Cataluña hasta 1653 , en la que murieron 400 miembros de las tropas atacantes. $\mathrm{Al}$ día siguiente se rindió la población que estaba en el castillo. En 1650, cuando hacía ya tiempo que la soldadesca de guarnición en la plaza no recibía su paga, el ejército castellano aprovechó de nuevo para tomar la ciudad. Vid.: SANABRE (1956). QUEROL \& MUÑOZ (2004).

44 PEDRELL \& ANGLÈS (1921): 135-151.

45 Pablo Marqués (fl.1651-1676). Maestro de capilla en la catedral de la Seu d'Urgell entre 1655 y 1676. Se conservan dos misas suyas en la Biblioteca de Catalunya, un villancico en Montserrat y algunas composiciones en el Orfeó Català de Barcelona. Aparece en las listas de la catedral de La Seu d'Urgell como ministril bajón desde 1651 hasta 1660. 
Y no obstante lo anterior, diversos autores anteriormente $\operatorname{citados}^{46}$ sitúan su muerte después de 1649 , en lo que, en cualquier caso, habría sido una breve segunda etapa en el cargo. Con estos datos, se cerraría la etapa de vida conocida hasta ahora de Juan Arañés.

\section{BIBLIOGRAFÍA}

Bernardó, Màrius, "Lleida [Lérida]", Diccionario de la Música Española e Hispanoamericana. Madrid, SGAE, 1999, vol. 6, 946.

Calahorra Martínez, Pedro, Historia de la música en Aragón. (Siglos I-XVII). Zaragoza, Librería General, 1977.

Calahorra Martínez, Pedro, La Música en Zaragoza en los siglos XVI y XVII. 2. Polifonistas y ministriles. Zaragoza, Institución Fernando el Católico, 1978.

Calahorra Martínez, Pedro, "Muniesa, Jerónimo", Gran Enciclopedia Aragonesa. Zaragoza, Unali, 1981, vol. 9, 2389.

Cerveró Martínez, Francisco Javier, Juan Arañés y su libro segundo de tonos y villancicos...con la cifra de la guitarra española a la usanza romana (Roma, Juan Bautista Robletti, 1624). Tesis doctoral, Valencia, Universidad Politécnica de Valencia, 2017.

Cortès i Mir, Francesc, "Urgellés, Gaspar", Diccionario de la Música Española e Hispanoamericana. Madrid, SGAE, 2002, vol. 10, 580 .

Dadson, Trevor J., "Inventario de los cuadros y libros de Ruy Gómez de Silva, III Duque de Pastrana (1626)", Revista de Filología Española, 67/3-4 (1987), 245-268.

Ezquerro Esteban, Antonio, "Músicos del Seiscientos Hispánico: Miguel de Aguilar, Sebastián Alfonso, Gracián Babán y Mateo Calvete", Anuario Musical, 61 (Barcelona, 2006): 81-120.

Fétis, François Joseph, Biographie universelle des musiciens et bibliographie générale de la musique. París, Firmin Didot, 1875, vol. 1, 125.

García Cueto, David, "El viaje a España de Cosme Lotti y las fuentes de Roma, Tívoli y Frascati”, Archivo Español de Arte, 80/319 (julio-septiembre 2007), 307-334.

Honegger, Marc, “Arañés, Juan”, Diccionario de la Música. Los hombres y sus obras. Madrid, Espasa-Calpe, 1988, vol. 1,32 .
Mitjana y Gordón, Rafael, "La Musique en Espagne (Art Religieux at Art Prophane)", Encyclopédie de la Musique et Dictionnaire du Conservatoire. París, Delagrave, 1920 [traduc.: Martín Moreno, Antonio (pról.) y Álvarez Cañibano, Antonio (ed.): La Música en España. Madrid, Centro de Documentación Musical, INAEM, 1993, 116].

Molí Frígola, Montserrat, "Compositores e intérpretes españoles en Italia en el siglo XVIII", Cuadernos de Sección. Música, 7 (1994), 9-125.

Mujal Elías, Juan, Lérida. Historia de la música. Lleida, Dilagro, 1975, 89, 90 y 93.

Pavia i Simó, Josep, La música a la catedral de Barcelona, durant el segle XVII. Barcelona, Fundació Salvador Vives i Casajuana, 1986, 202-203.

Pedrell Sabaté, Felip y Anglès Pàmies, Higini, Els madrigals i la missa de difunts d'en Brudieu. Barcelona, Institut d'Estudis Catalans, 1921.

Pedrell Sabaté, Felipe: "Documentos inéditos para su Diccionario", en $\boldsymbol{E}-B b c$, M 942.

Querol Coll, Enric y Muñoz i Sebastià, Joan Hilari, La Guerra dels Segadors a Tortosa (1640-1651). Valls (Tarragona), Cossetània Edicions, 2004.

Querol Coll, Enric, Estudis sobre cultura literària a Tortosa a l'edat moderna. Barcelona, Publicacions de l'Abadia de Montserrat, 2006.

Salazar y Castro, Luis de, Historia genealógica de la Casa de Silva, donde se refieren las acciones más señaladas de sus señores, las fundaciones de sus mayorazgos y la calidad de sus alianças matrimoniales. Madrid, Melchor Álvarez y Mateo de Llanos, 1685, vol. 2, 565-566.

Sanabre i Sanromà, Josep, La acción de Francia en Cataluña en la pugna por la hegemonía de Europa. Barcelona, Librería J. Sala Badal, 1956.

Stevenson, Robert Murrell, "Arañés [Arañiés], Juan”, The New Grove Dictionary of Music and Musicians. Londres, Macmillan, 1980, vol. 1, 542.

Stevenson, Robert Murrell, "Arañés [Arañiés], Juan", The New Grove Dictionary of Music and Musicians. OxfordNueva York, Macmillan, Oxford University Press, 2001, vol. 1,837 .
46 FÉTIS (1875), MITJANA (1920), STEVENSON (1980) y HONEGGER (1988).
Recibido: 09.01.2018

Aceptado: 14.04.2018 